\title{
An annual cycle of long lived stratospheric gases from MIPAS
}

\author{
M. N. Juckes \\ British Atmospheric Data Centre, SSTD, Rutherford Appleton Laboratory, Chilton, Didcot, Oxfordshire, OX11 0QX, UK
}

Received: 20 July 2006 - Published in Atmos. Chem. Phys. Discuss.: 26 September 2006

Revised: 8 January 2007 - Accepted: 31 March 2007 - Published: 16 April 2007

\begin{abstract}
MIPAS, on ENVISAT, has made high quality observations of ozone, methane and water vapour. Gridded fields, at 4 hourly intervals and, have been calculated for all of 2003 using data assimilation with isentropic advection as a constraint. The gridded fields are validated against independent measurements (from 7 other instruments in the case of ozone, 3 for water vapour and one for methane). For ozone the results are in agreement with previously published results. For water vapour the bias relative to HALOE is below $10 \%$ between 20 and $48 \mathrm{~km}$, and the standard deviation is below $12 \%$ in this range. Departures from SAGE II and POAM III are substantially larger. The methane analysis has a bias of less than 5\% relative to HALOE between 23 and $40 \mathrm{~km}$, with a standard deviation less than $10 \%$ in this height range. The water vapour field clearly reflects the upward motion in the lower tropical stratosphere, while both water vapour and methane show the signature of advection higher up. In the polar regions the descent in the vortex is clearly visible, with strong descent in autumn giving way to weaker descent through the winter. Descent rates of around $10^{-3} \mathrm{~ms}^{-1}$ are found during the formation of the polar vortices, slowing to around $3 \times 10^{-4} \mathrm{~ms}^{-1}$ during the winter. Ascent of around $2 \times 10^{-4} \mathrm{~ms}^{-1}$ in the tropics is revealed by the water vapour and total observed hydrogen fields (4 times the methane plus twice the water vapour concentration). The total observed hydrogen is depleted in the polar upper stratosphere when air is advected down from the upper mesosphere.
\end{abstract}

\section{Introduction}

Stratospheric water vapour and methane are important greenhouse gases. Methane has been increasing steadily due to anthropogenic emissions. Water vapour has also been increasing, in part due to oxidation of the increasing methane content (e.g. Rosenlof et al., 2001; Rind and Lonergan, 1995; Shindell, 2001, but see also Randel et al., 2006).

Correspondence to: M. Juckes

(m.n.juckes@rl.ac.uk)
Michelson Interferometer for Passive Atmospheric Sounding (MIPAS) instrument on the ENVISAT ${ }^{1}$ (Fischer and Oelhaf, 1996; Tsidu et al., 2003; Glatthor et al., 2005) was operational at full resolution for 20 months. The central 12 month period (January to December 2003) had near continuous global coverage. This gives unprecedented resolution of the day to day evolution of these key gases. This paper presents assimilated fields of ozone, methane and water vapour. The assimilation algorithm is exactly as described in Juckes (2006) (hereafter J2006). Isentropic advection is used as a constraint. No account is taken of vertical structure: the analysis is carried out independently on each of 15 isentropic surfaces.

Assimilation of MIPAS ozone data has been discussed in Geer et al. (2006) and J2006. Here, new results for methane and water vapour are introduced. These two gases are important in their own right as significant players in the radiation budget (e.g. Shine, 1993), but also serve to illustrate the stratospheric circulation. The role of the polar vortex as a distinct air mass with special chemical properties has been a matter of special interest since the development of the Antarctic polar ozone hole (Farman et al., 1985; Solomon et al., 2005). The observation track of MIPAS crosses the pole every orbit, giving exceptional coverage of this key region of the stratosphere.

The next section summarises the methods used. Section 3 then describes the validation against independent measurements. Section 4 looks at the annual cycle in the 3 assimilated species. Section 5 looks at the evolution on shorter time scales, showing how the assimilated fields faithfully track a strong disturbance to the polar vortex. Section 6 looks at equivalent zonal means and introduces the total observed hydrogen.

\footnotetext{
${ }^{1}$ The European Space Agency's 'Environmental Satellite', launched on Friday 1 March 2002.
} 
(a)

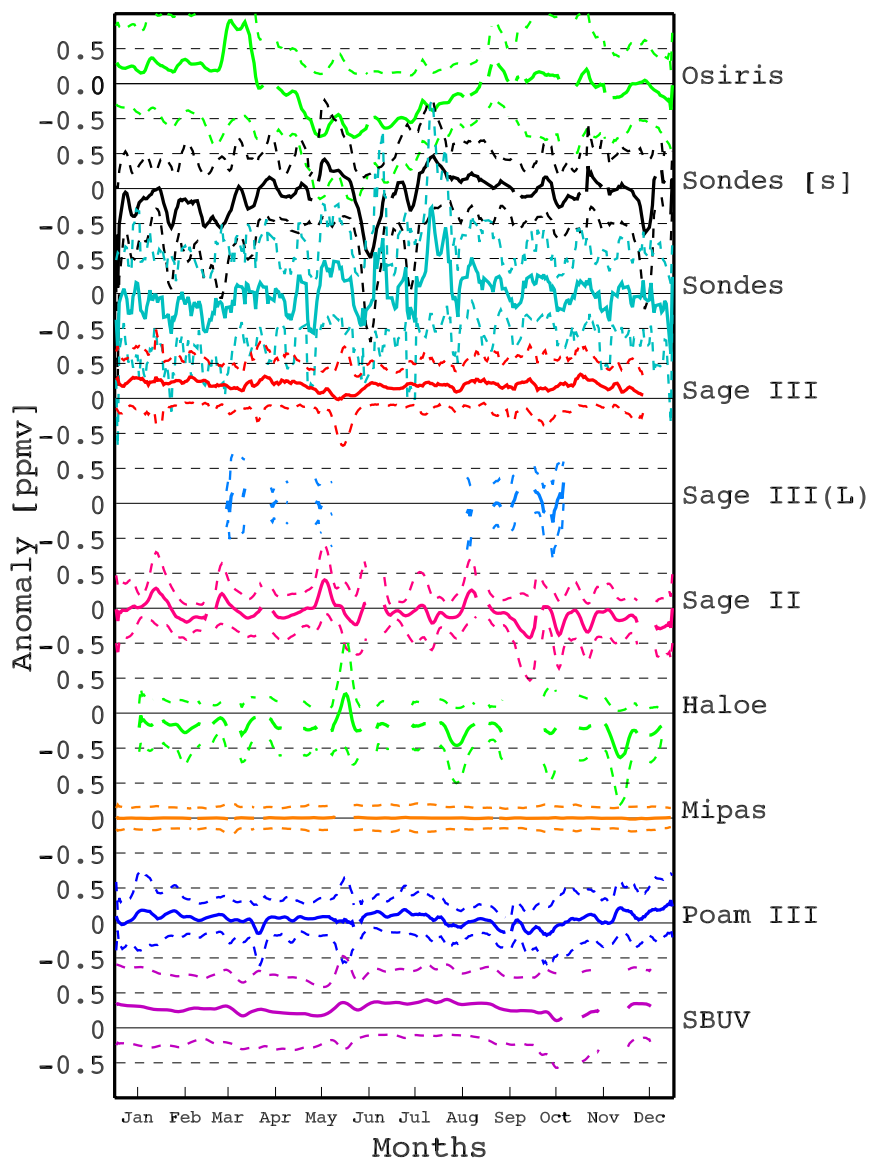

Fig. 1. Time sequence of observation minus assimilation on the $850 \mathrm{~K}$ isentropic surface. (a) The mean for each day, taken over all observations on that day, is plotted as solid lines, with dashed lines at plus/minus one standard deviation. (b) monthly means and standard deviations by latitude bands. Each latitude band is divided into 12 months, with April, May, June and October, November, December shaded. For each month, where data is present, a vertical bar marks the mean observation minus analyses, and the arrows plus and minus one standard deviation. A bar without arrows occurs when there is a single validating observation in that month and latitude band. Bars are drawn dashed when they overlap bars higher up the graphic. In (a) and (b), SAGE III [L] is the data from the lunar occultation mode of SAGE III. Sondes [S] is data from the WOUDC ozone sondes which has been vertically smoothed with a $2 \mathrm{~km}$ running mean.

\section{Methodology and data}

The MIPAS level 2 offline product (ESA, 2004) was used, versions 4.59 (2772 profiles), 4.61 (213284) and 4.62 (25328). The offline product has been found to be significantly improved over the near-real time product (e.g. Fonteyn et al., 2004). The fields are interpolated onto isentropic surfaces prior to assimilation using the MIPAS retrieved tem-

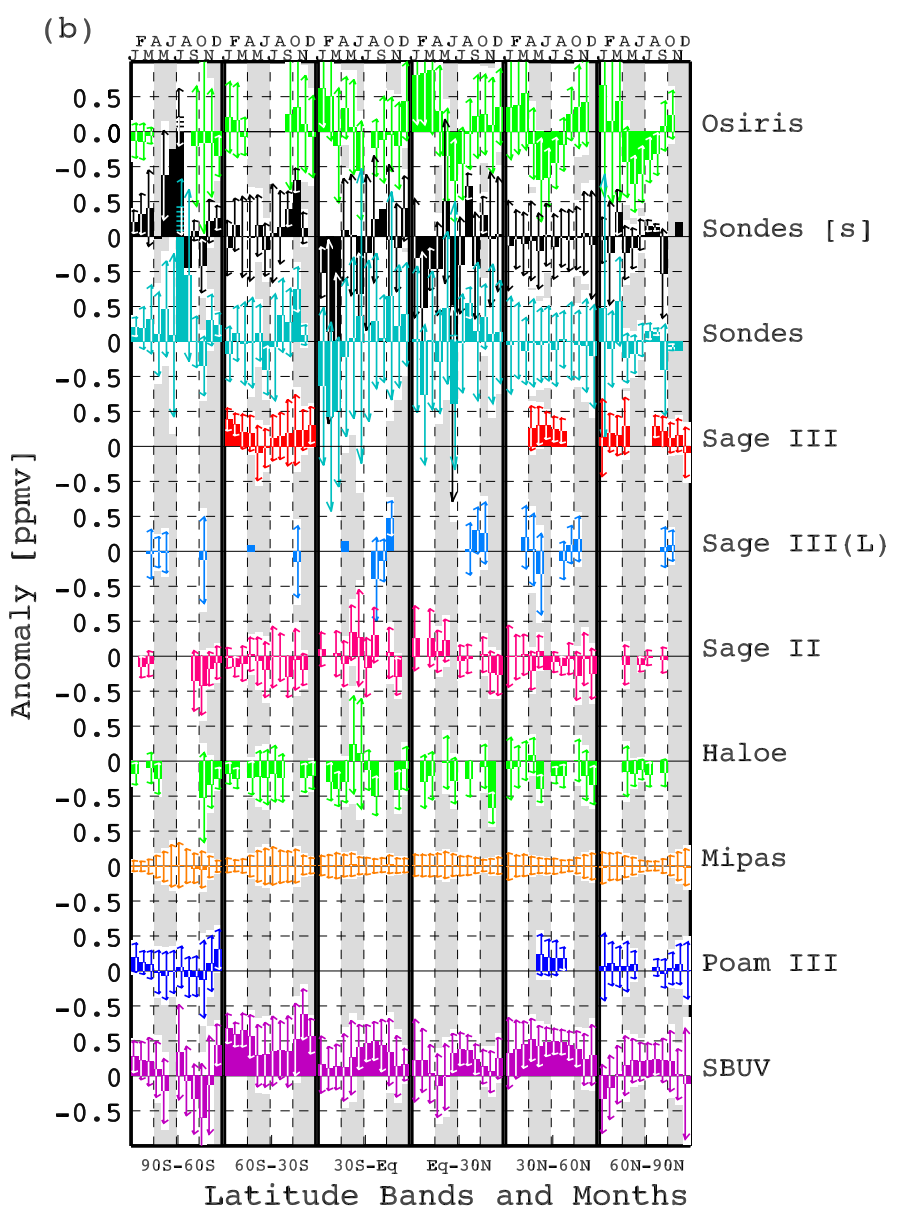

Fig. 1. Continued.

perature profiles and linear interpolation with respect to potential temperature.

The assimilation uses meteorological fields from the European Centre for Medium-Range Weather Forecasts (ECMWF) operational analyses.

As in J2006, the assimilation is computed as the minimisation of a single cost function:

$$
\begin{aligned}
\mathcal{J} & =\sum_{i} \sigma_{\text {obs: } i}^{-2}\left[\chi_{\text {obs: } i}-\chi\left(\lambda_{\text {obs }: i}, \phi_{\text {obs }: i}, t_{\text {obs }: i}\right)\right]^{2} \\
& +\iint\left\{w_{\text {ap }}\left[\chi_{t}+\mathbf{u} \cdot \nabla \chi\right]^{2}\right. \\
& \left.+w_{\text {num }}\left|\left(c_{1} \frac{\partial}{\partial t}, \nabla\right)\left(c_{1}^{2} \frac{\partial^{2} \chi}{\partial t^{2}}+\nabla^{2} \chi\right)\right|^{2}\right\} d A d t
\end{aligned}
$$

where $\chi$ is the tracer mixing ratio in units of ppmv (parts per million by volume), $\lambda, \phi, t$ are longitude, latitude and time respectively, $\mathbf{u}$ is the horizontal wind velocity, $\sigma_{\text {obs:i }}^{2}$ is the observation error variance, with the subscript $i$ here and elsewhere labeling the observation. Constants 
used here are $c_{1}=0.5$ days per radian $=0.0068 \mathrm{~s} \mathrm{~m}^{-1}$, $w_{\text {ap }}=50$ day $^{2} \mathrm{ppmv}^{-2}=3.7 \times 10^{11} \mathrm{~s}^{2} \mathrm{ppmv}^{-2}, \quad$ and $w_{\text {num }}=1.45 \times 10^{-6} \operatorname{radian}^{6} \mathrm{ppmv}^{-2}=9.7 \times 10^{34} \mathrm{~m}^{6} \mathrm{ppmv}^{-2}$. The summation is over all observations, and the integrations are over the sphere $(d A=\cos \phi d \lambda d \phi)$ and over an assimilation window of around 50 days. The large value of the $w_{\text {num }}$ in SI units reflects the scale-selectivity of this term, which ensures the solution is well behaved on the grid scale. There are no prescribed error covariance structures in this formulation: the variational problem is completely defined by the constants quoted above and the observational data ( $\chi_{\text {obs:i }}, \sigma_{\text {obs:i }}, i=1, N_{\text {obs }}$, where $N_{\text {obs }}$ is the number of observations). $\chi$ is the tracer mixing ration and $\sigma$ the error variance estimate.

The solution is found by solving $\mathcal{A}[\chi]=0$, where $\mathcal{A}$ is the differential operator resulting from the first variation of Eq. (1) with respect to $\chi$. The solution method and the choice of constants $c_{1}, w_{\text {ap }}$ and $w_{\text {num }}$ is discussed in more detail in J2006.

The spatial and temporal discretisation used here are 1.875 degrees and $4 \mathrm{~h}$ respectively, with longitudinal thinning of the grid towards the pole as described in J2006. The analysis period is split into 12 monthly assimilation windows, each extending around 50 days from the 21 st of the previous month through to the 10th of the subsequent month. Two exceptions to this rule are the January window, which starts on 1 January, and the December window, which ends on 31 December. As described in J2006, the analysis from the ends of each assimilation window (with the exception of the start of January and end of December) is discarded.

\section{Validation}

Validation data was employed from the following instruments (with level 2 data version in square brackets): Solar Backscatter Ultraviolet (SBUV; Planet et al., 2001)[61610], Stratospheric Aerosol and Gas Experiment (SAGE II and III; Thomason and Taha, 2003)[6.2], Polar Ozone and Aerosol Measurement (POAM III; Lumpe et al., 2003; Pierce et al., 2003)[4], Optical Spectrograph and Infrared Imaging System (OSIRIS; von Savigny et al., 2003)[1.2], and Halogen Occultation Experiment (HALOE; Brühl et al., 1996)[19]. In addition ozonesonde data provided by the World Ozone and Ultraviolet Radiation Data Centre (WOUDC) ${ }^{2}$, from 38 stations listed in the appendix of J2006, was used. Table 1 shows the average number of profiles per day used form each instrument (and each mode of operation for SAGE III) in this study.

\footnotetext{
${ }^{2}$ WOUDC is one of five World Data Centres which are part of the Global Atmosphere Watch programme of the World Meteorological Organization. The WOUDC is operated by the Experimental Studies Division of the Meteorological Service of Canada (web address: http://www.woudc.org)
}

(a)

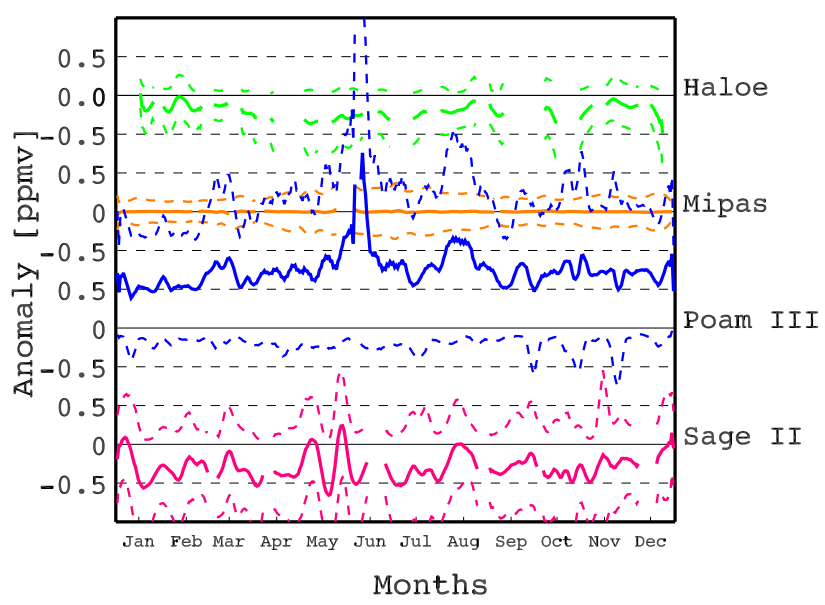

(b)

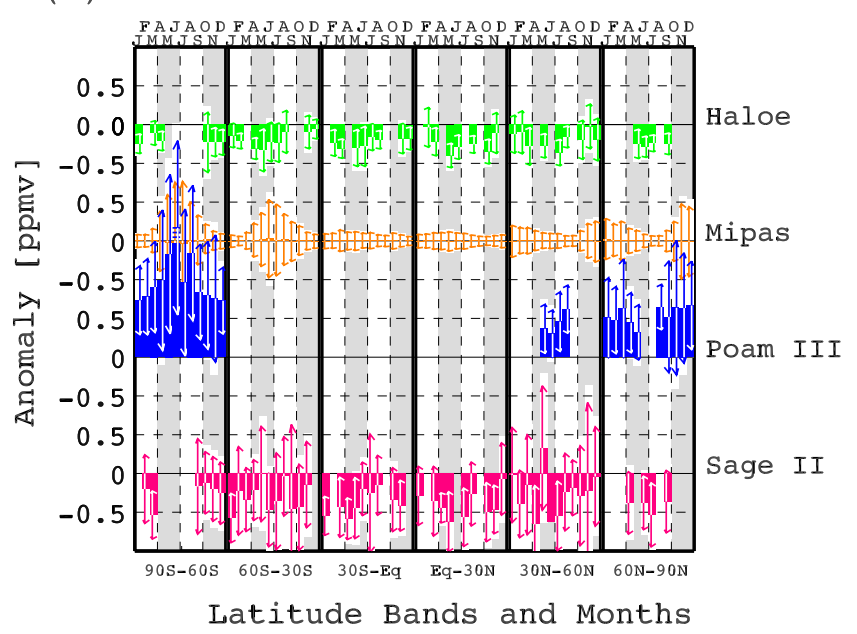

Fig. 2. As Fig. 1, except for water vapour.

The validation fields are interpolated with their own retrieved temperature profiles where available (ozonesondes, HALOE), temperature profiles distributed with the data (SAGE, POAM, both of which use NMC temperatures), or with ECMWF temperatures interpolated to the profile position (SBUV and OSIRIS).

J2006 validated 6 months of ozone data. Here, that analysis has been extended to 12 months. The results for ozone do not differ significantly from those reported earlier. Figure 1 shows a summary of the ozone validation against independent observations on the $850 \mathrm{~K}$ isentropic surface. The assimilated MIPAS field shows no significant drift relative to SBUV, HALOE, SAGE II or SAGE III. There is large variability relative to OSIRIS and ozone sondes, but this does not appear to be systematic (it should be noted that this level, $850 \mathrm{~K}$ - approximately $30 \mathrm{~km}$, is towards the upper limit of the sondes' range). Overall, the majority of comparisons support the view that the bias in MIPAS is small and without 
Table 1. Average number of profiles per day [ppd] used in this study.

\begin{tabular}{rrrrr}
\hline Instrument & Ozone ppd & Water Vapour ppd & Methane ppd & Comments \\
\hline Haloe & 13.2 & 12.4 & 10.9 & \\
Mipas & 650 & 622 & 625 & \\
Osiris & 165 & - & - & \\
Poam III & 14.3 & 14.4 & - & High latitude only \\
SBUV & 1021 & - & - & Daytime only \\
Sage II & 12.5 & 12.5 & - & \\
Sage III & 24.2 & - & - & High latitude only \\
Sage III(L) & 0.9 & - & - & \\
WOUDC Ozonesondes & 3.2 & - & - & Up to 850 K \\
\hline
\end{tabular}

(a)

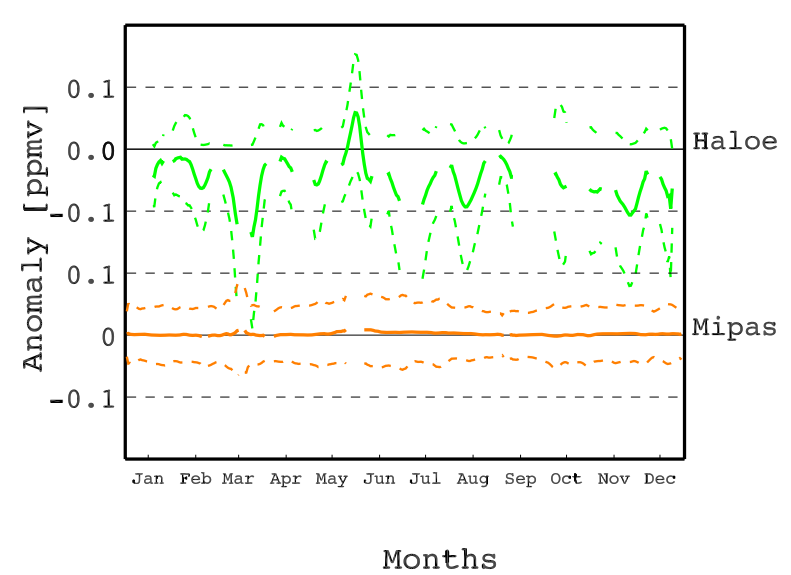

(b)

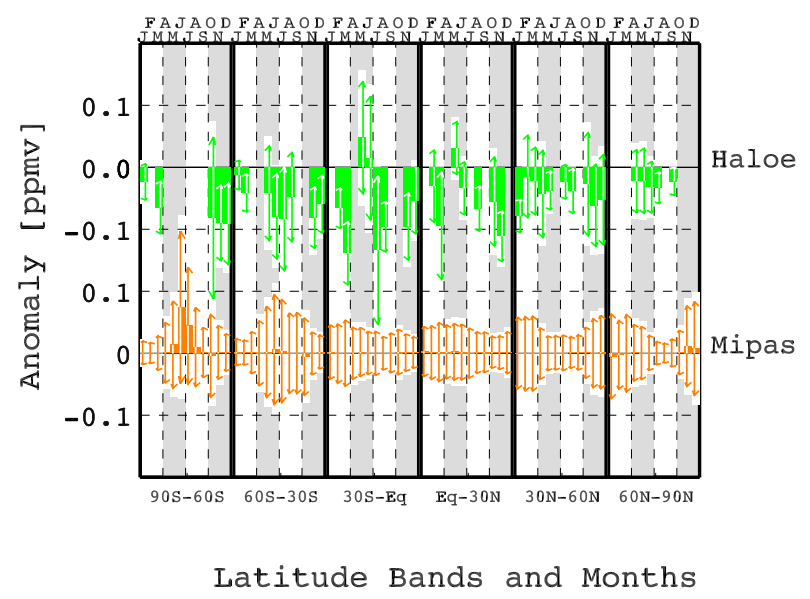

Fig. 3. As Fig. 1, except for methane.

systematic drift.

Figure $1 \mathrm{~b}$ shows mean and standard deviations for 6 latitude bands (each covering 30 degrees). Unlike Fig. 1a, this figure reflects the localised nature of POAM III and SAGE III (in solar occultation mode), both of which only observe at high latitudes. In most latitude bands, the OSIRIS observations reflect the pattern seen in the daily, all-observation, means of Fig. 1a. South of $30 \mathrm{~S}$, however, the mean departures from the analysis are consistently small. The sondes show best agreement in the $30-60 \mathrm{~N}$ band, with near zero mean anomalies. Well over half the sonde profiles are in this band with, on average, over 50 profiles per month, whereas the other latitude bands average between $6(60 \mathrm{~N}$ to $90 \mathrm{~N})$ and 13 profiles per month (30 S to Equator). However, even in the $30-60 \mathrm{~N}$ band the standard deviations ( 0.4 to $0.74 \mathrm{ppmv}$ ) are generally larger than those relative to HALOE (0.12 to 0.44 ppmv), POAM III (0.16 to $0.3 \mathrm{ppmv})$ and SAGE III (0.18 to 0.28 ppmv).

Figure 2 show the same diagnostics for the water vapour fields. The closest agreement is with HALOE, with standard deviations around $0.25 \mathrm{ppmv}$. Both HALOE and SAGE II measure consistently low values relative to the analysis. POAM III (observations at high latitudes only) measures high relative to the analysis. There is no significant drift against the validation instruments.

Figure 3 shows the comparison for methane: there is only one validation instrument, HALOE. The amplitude of the mean differences increases slightly through the year, ending with HALOE reading 0.05 ppmv lower than the MIPAS assimilation.

In Figs. 1-3 the orange curve shows the mean and standard deviation of the MIPAS observations minus analysis. The global mean is very close to zero in all cases, as expected from the construction of the analysis (J2006). There is a mean difference in the methane observations minus analysis in the 90S-60S band during the southern winter (Fig. 3b). This is a period where coverage in the southern vortex is low: 658 profiles in that latitude band in June compared with 3952 in March. The standard deviations increase significantly both in June and July in the Southern hemisphere (the $90 \mathrm{~S}$ to $60 \mathrm{~S}$ and $60 \mathrm{~S}$ to $30 \mathrm{~S}$ bands) and in November and December at high Northern latitudes (the $60 \mathrm{~N}$ to $90 \mathrm{~N}$ band). This is 
(a)

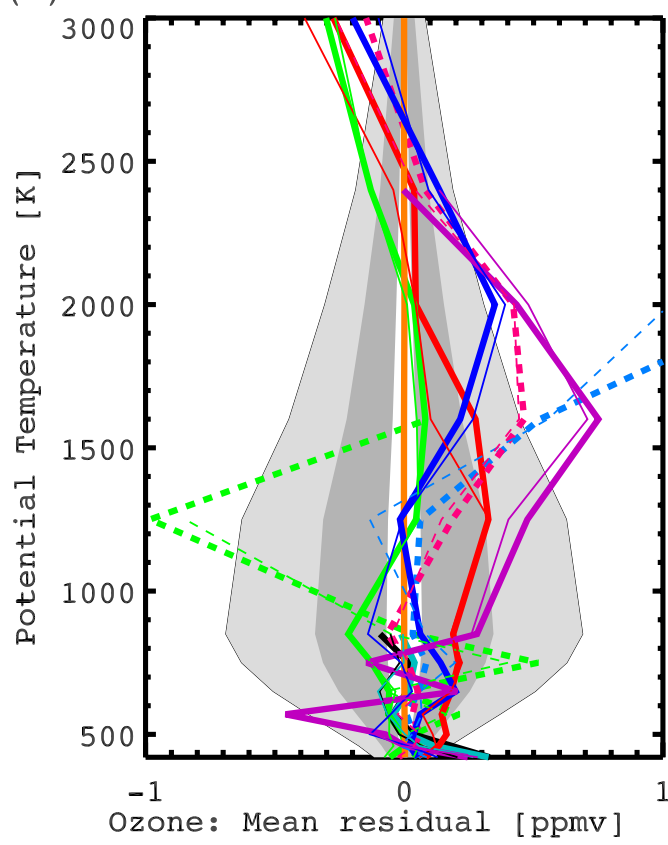

Fig. 4. Vertical profile of ozone (a) mean error (observation minus assimilation) and (b) standard deviation (root mean square differences after subtraction of the mean) against potential temperature. The shading shows $1-5 \%$ (dark) and $5-10 \%$ (light) of the mean assimilation profile (averaged over all the validation points). Additional thin lines show nearest-neighbour validation profiles. These are the mean difference between MIPAS level 2 profiles and those of the other instruments taken over all pairs occurring within $2.5 \mathrm{de}$ grees and $6 \mathrm{~h}$ of each other. The corresponding standard deviations of near-neighbour pairs are not shown as their inclusion makes the figure too noisy.

visible in all three species, but is strongest in the water vapour (Fig. 2b). Water vapour also has low coverage in the southern winter vortex (1083 profiles in the southern latitude band in June), though not as bad as for methane. Where there are validating HALOE retrievals, in June and July, $60 \mathrm{~S}$ to $30 \mathrm{~S}$, the assimilation has a lower standard deviation relative to the independent HALOE data than it does relative to the observations used as input. The high level of noise in the data has been commented on by Lahoz et al. (2006). The comparison against POAM III shows enhanced bias and variability. It can be seen from seasons and latitude bands where both HALOE and POAM III are compared against MIPAS that the standard deviations of the comparison against POAM III are systematically higher than those against HALOE, so not all of the variance in the POAM III residuals can be attributed to the MIPAS analysis.

Figure 4 shows vertical profiles of the isentropic mean and standard deviation of the observations minus analysis for the ozone data (global and annual average, taken over all available observations). The structure over the 12 month period
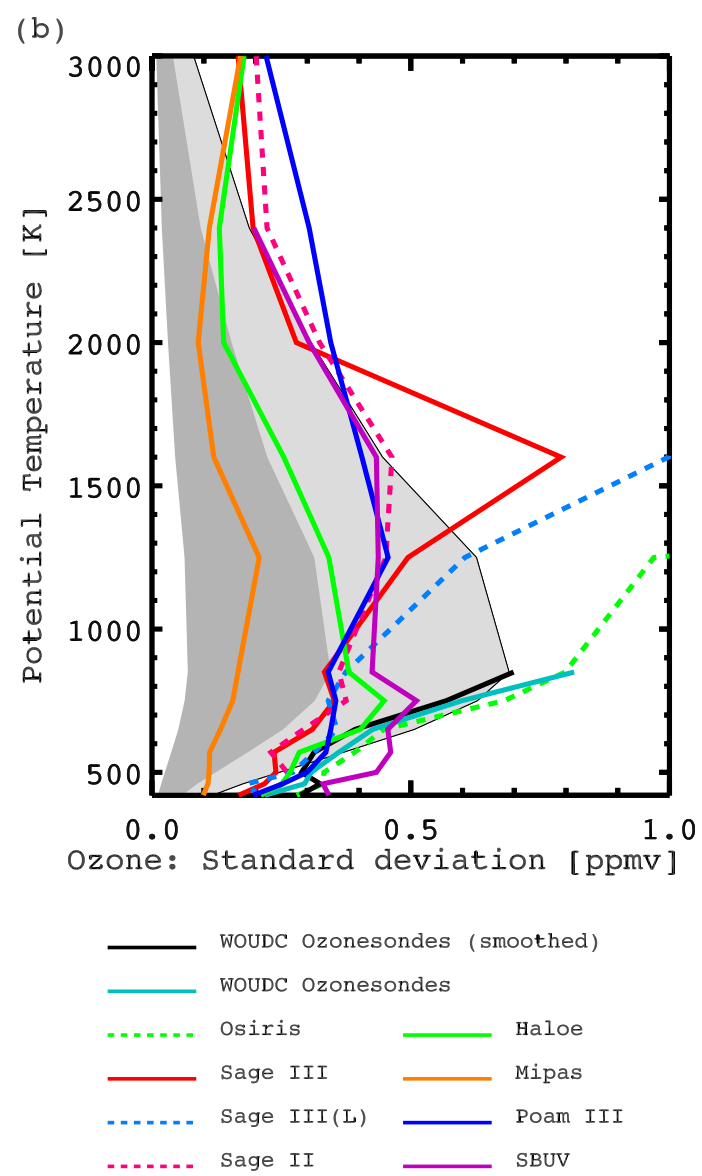

Fig. 4. Continued.

studied here is essentially the same as the 6 month period analysed in J2006. Mean differences are small between 500 and $1250 \mathrm{~K}$ (i.e. approximately from 20 to $40 \mathrm{~km}$ - heights of isentropic surfaces can be read from Fig. 7 below). Above and below that range it appears that MIPAS is measuring low.

The water vapour mean and standard deviation profiles (Fig. 5) are ambiguous. MIPAS has higher water vapour values than HALOE but is close to POAM III in the upper stratosphere (around 1000 to $2000 \mathrm{~K}$; this study was initially done with POAM III version 3 data which was closer to HALOE, in the diagnostic presented in Fig. 5, than to MIPAS: but version 4 is substantially moister in this region). Between $500 \mathrm{~K}$ and $850 \mathrm{~K}$ the biases relative to SAGE II and HALOE are small (around 5\%), but there are larger biases relative to POAM III in the mid and lower stratosphere. Milz et al. (2005), using MIPAS data with a different retrieval process, found smaller biases relative to HALOE below $35 \mathrm{~km}$, but biases exceding $10 \%$ from 40 to $45 \mathrm{~km}$. Pan et al. (2002) evaluated ILAS water vapour profiles and found values $10 \%$ to $20 \%$ higher than HALOE in the $800 \mathrm{~K}$ to $1800 \mathrm{~K}$ height range. Payne (2005) analysed possible sources of a high bias in MIPAS water vapour in the retrieval algorithm, but did not 
(a)

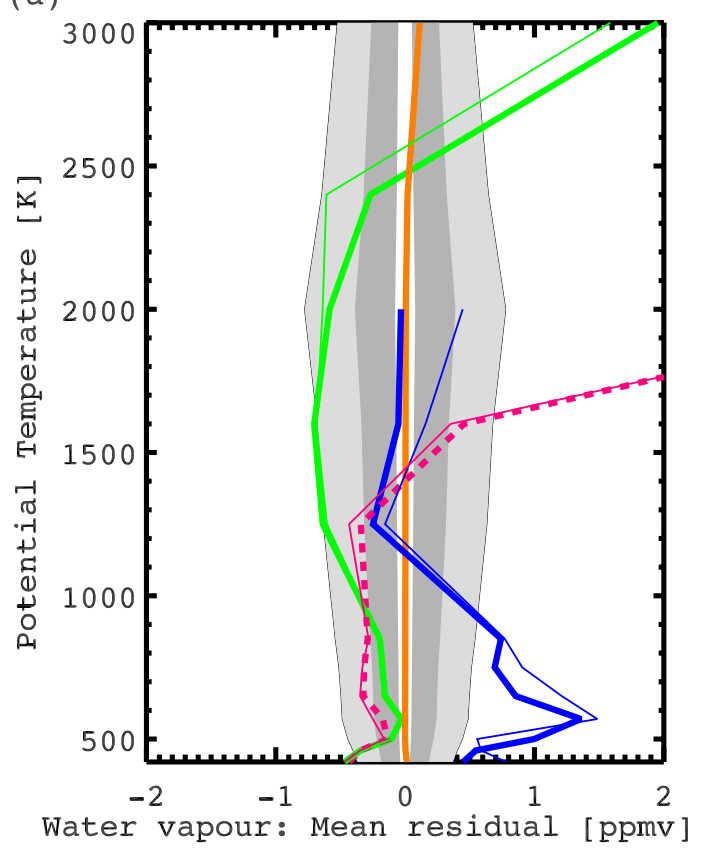

(b)

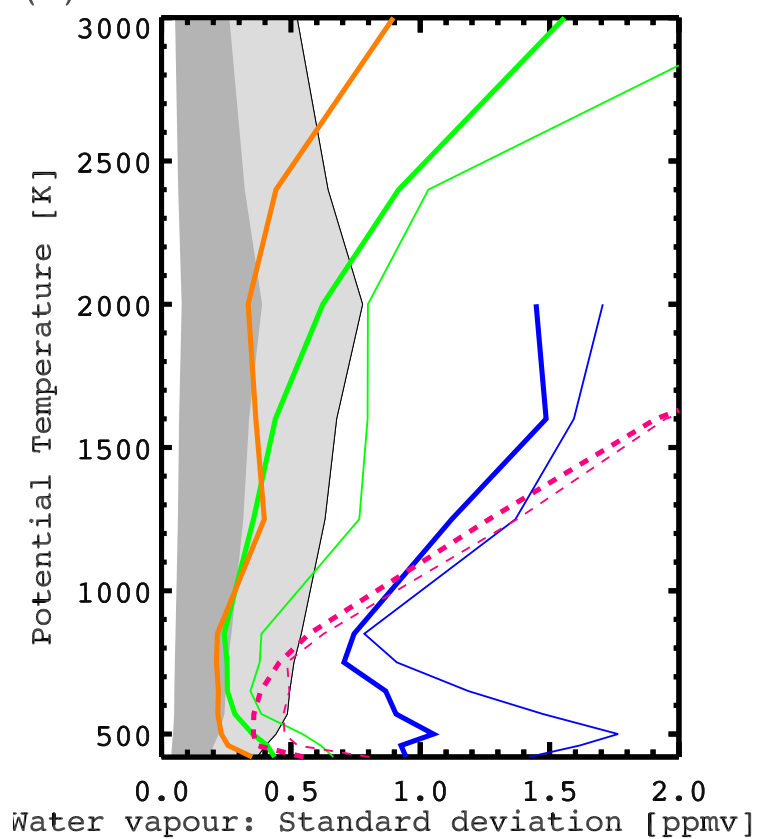

Fig. 5. As for Fig. (4), except for water vapour.

find anything which could explain the offset between MIPAS and HALOE. This issue is discussed further below in Sect. 6.2.

As with the $850 \mathrm{~K}$ time series shown in Fig. 2, the standard deviation of the difference between the HALOE measurements and the assimilation is less at one level $(1250 \mathrm{~K})$ than the standard deviation of the difference between the assimilation and the observations which were used to create it (this is not the case for the root-mean-square difference). One possible explanation is that the assimilation of the data is reducing the random error present in the input data through the smoothing effect inherent in the variational assimilation of noisy data (e.g. Juckes and Lawrence, 2006). In terms of the standard deviation, the agreement with HALOE is substantially better than that with POAM III at all levels and better than that with SAGE II above $500 \mathrm{~K}$.

Figure 6 shows profiles of mean anomaly and standard deviation of the methane analyses relative to HALOE observations. There is a positive relative bias in the analyses at all heights, less than $5 \%$ between $600 \mathrm{~K}$ and $1700 \mathrm{~K}$. The standard deviation is under $10 \%$ over this height range.

For both water vapour and methane, Figs. 5 and 6 also show results of a nearest neighbour comparison between the MIPAS profiles used as input for the assimilations and the validating data. The mean differences are very similar to those found with the assimilated data, but the standard deviation are larger in the nearest neighbour comparisons. This may be due to the ability of the assimilation to accurately represent spatial and temporal changes and to filter out noise, as indicated above.

All the validation data (in the form of differences between analyses and validating observations) are available as netcdf files (see supplementary material http://www.atmos-chem-phys.net/7/1879/2007/ acp-7-1879-2007-supplement.zip).

\section{Annual cycle}

The annual cycle of methane and water vapour has been discussed by Randel et al. (1998); Dunkerton (2001), using HALOE data. The evolution of the present data through the year reproduces the main features highlighted in previous studies. Figure 7 shows time-height sections of ozone, water vapour and methane, averaged in 3 equivalent latitude bands. ${ }^{3}$ Averaging around equivalent latitude bands results in greater continuity because the averaging volume follows the short period dynamical displacements of the airmass. A 9 day period at the end of May during which there are no MIPAS observations is blanked out of the plots.

The equivalent zonal mean water vapour in the tropics (Fig. 7h) shows a very clear "tape recorder" signal (Mote et al., 1996, 1998; Randel et al., 1998): that is, a pattern imprinted on the air at the tropopause is carried upwards in the rising branch of the Brewer-Dobson circulation, rising at around $2 \times 10^{-4} \mathrm{~ms}^{-1}$ (the slope of the red arrow in Fig. $7 \mathrm{~h}$ ),

\footnotetext{
${ }^{3}$ The equivalent latitude, $\phi_{\text {equiv }}$, is defined to be constant on contours of Ertel's potential vorticity, $P V$, and valued such that the total area over which $P V>P V_{0}$ is given by $4 \pi\left\{1 .-\cos \left[\phi_{\text {equiv }}\left(P V_{0}\right)\right]\right\}$.
} 
consistent with the value given by Mote et al. for the northern summer. The higher value they quoted for the northern winter $\left(4 \times 10^{-4} \mathrm{~ms}^{-1} \equiv 1 \mathrm{~km} / \mathrm{month}\right)$ is not seen here (their analysis covered more years and extended lower than the data presented here, so there is no contradiction). The ascent rate seen here is very close to the $0.7 \mathrm{~km} / \mathrm{month}\left(2.7 \times 10^{-4} \mathrm{~ms}^{-1}\right)$ given by Randel et al. (1998).

In the tropical mid and upper stratosphere $(35 \mathrm{~km}$ and above) methane and water vapour show the semi-annual oscillation seen in Randel et al. (1998). At these heights, in contrast to the lower stratosphere, the isolines of these two species follow each other closely. This reflects the fact that the anomalies in this region are controlled by a balance between advection and chemical relaxation (Dunkerton, 2001), so that the structure in the anomalies represents the variation in the upward advection. In the lower stratosphere the presence of the tropical tape-recorder reflects the fact that the chemical relaxation is slower and the anomalies reflect the air mass history.

The polar regions show a larger annual cycle and greater short term variability, primarily in the winter months. The evolution of the temperature structure is shown in Fig. 8 (see also Fig. 10 below). In the lower stratosphere, southern hemisphere, the coldest temperatures are reached in July and August. At $40 \mathrm{~km}$, by contrast, the coldest temperatures occur just after the equinox. The onset of gradual warming after that date coincides with an increase in variability, as shown in Fig. 9. At the end of the winter there is a sharp rise in the pressure, such that there is a sudden drop in potential temperature towards the end of the winter (this shows up as a step in the green isentropes in Fig. 8a). This is somewhat counterintuitive, as it coincides with rising temperatures: however, at this height, the affect of the rising pressure on the potential temperature outweighs that of the temperature.

Returning to the tracer fields shown in Fig. 7: in Fig. 7a we see the onset of chemical ozone loss at $20 \mathrm{~km}$ in late September (Farman et al., 1985; Crutzen and Arnold, 1986; Crutzen and Lelieveld, 2001) in the southern vortex. Geer et al. (2006) show that MIPAS underestimates the extent of this loss, but it is nevertheless clearly distinguishable from the midwinter maximum in ozone seen in the northern hemisphere. The ozone loss is preceded by drying out of the lower stratosphere in late June (Fig. 7b).

In the mid stratosphere, the polar methane shows strong descent in the late summer and autumn followed by weaker descent throughout the winter. The overall pattern is as reported by Randel et al. (1998), but the present data resolve this with better temporal resolution than HALOE and it is possible to see marked switch in behaviour between the autumn and winter regimes. In the upper stratosphere [40 to $50 \mathrm{~km}$ ] there is a pronounced minimum, in both hemispheres, around the equinox at the start of the winter season, with mean values falling below 0.1 ppmv (Mar. in Fig. 7c, Sep. in Fig. 7f). This coincides with the onset of variability and the temperature minimum seen in Figs. 8, 9. Funke et al. (2005)
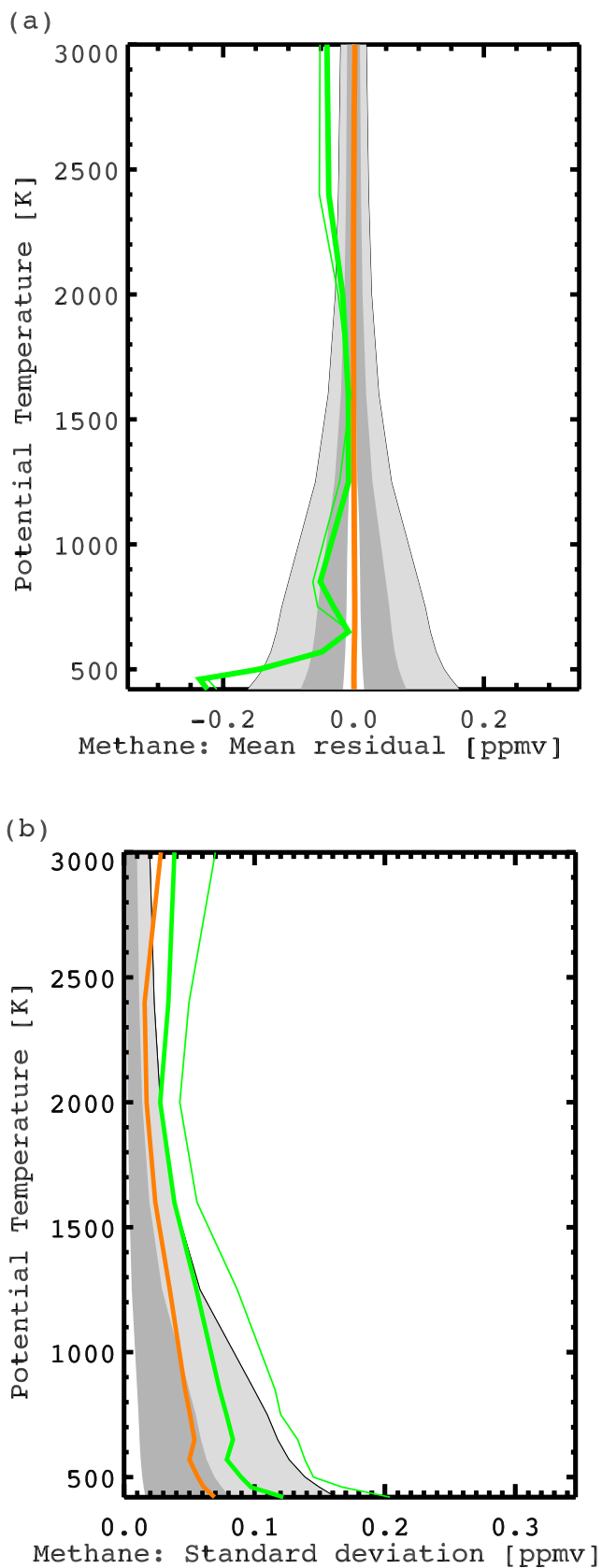

Fig. 6. As for Fig. (5), except for methane.

discuss the southern hemisphere event in more detail in the context of downward transport of $\mathrm{NO}_{\mathrm{x}}$ and conclude that that the initial minimum is the result of air descending from the mesosphere. The winter season in the northern hemisphere is not illustrated as clearly here because the study period only includes the end of one winter and the start of the next. It is, however, clear that the seasonal minimum methane concentration in the upper stratosphere $[45-50 \mathrm{~km}]$ is, similarly, shortly after the equinox. 

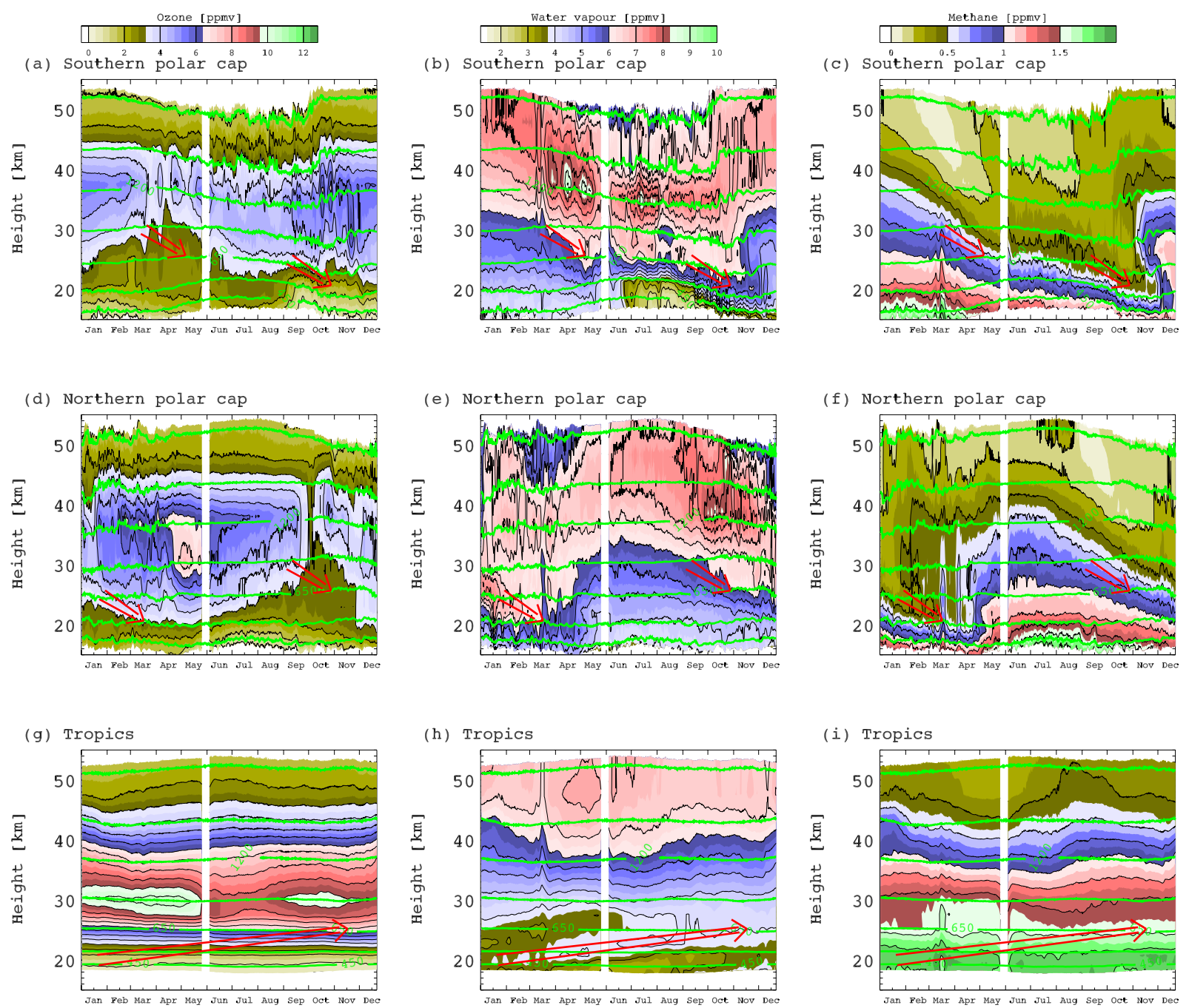

Month

Month

Month

Fig. 7. Time height sections of analyses averaged over equivalent latitude bands. The fields are: ozone (a, d, $\mathbf{g})$, water vapour (b, e, h) and methane (c, f, i). The equivalent latitude bands are: South of $80 \mathrm{~S}(\mathrm{a}, \mathrm{b}, \mathrm{c})$, north of $80 \mathrm{~N}(\mathrm{~d}, \mathrm{e}, \mathrm{f})$ and $5 \mathrm{~S}$ to $5 \mathrm{~N}$ (g, h, i). For each species the colour scale is given at the top of the column. The contour intervals are: $0.8 \mathrm{ppmv}$ (ozone), 0.5 ppmv (water vapour) and $0.2 \mathrm{ppmv}$ (methane). Isentropes are contoured in green, at 450, 520, 650, 850, 1200, 1650 and $2300 \mathrm{~K}$. In (a-f) red arrows slope downwards at a rate of $10^{-3} \mathrm{~ms}^{-1}$. In (g-i) red arrows slope upwards at a rate of $2 \times 10^{-4} \mathrm{~ms}^{-1}$.

From March to May the descent rate in the Southern polar vortex at $30 \mathrm{~km}$ is around $10^{-3} \mathrm{~ms}^{-1}$ (the slope of the red arrows in Figs. 7b, c). This is somewhat faster than cited in, for example Randel et al. (1998), but the difference is due to difference in vertical coordinates. Here, height has been used, whereas Randel et al. (1998) use log-pressure coordinates. Fig. 8 shows that the pressure surfaces descend at about $1 \mathrm{~km}$ per month in the Autumn. When this is taken into account the descent rates here are consistent with those in the literature (see also Schoeberl et al., 1995; Rosenfield et al., 1994).

The rapid descent rates seen in early October here match those deduced by Russell et al. (1993) from the distribution of water vapour and methane observed by HALOE at the end of October 1991. They concluded that the 15 to $20 \mathrm{~km}$ layer of the southern polar vortex was flushed out in one month, corresponding to around $1.9 \times 10^{-3} \mathrm{~ms}^{-1}$. Such descent rates are suggested by the isopleths descending rapidly in that layer in mid-October, but this rapid descent is short lived. Schoeberl et al. (1995); Rosenfield et al. (1994) looked at the descent rates using calculated heating rates. These calculations produced a substantially lower descent rates, consistent with the longer term descent at around $3 \times 10^{-4} \mathrm{~ms}^{-1}$ seen in Fig. 10c (arrow C). The observations analysed by Russell et al. (1993) nevertheless imply significant outward transport of air from the base of the vortex towards the end of the winter. McIntyre (1995) points out that mean isentropic outflow 


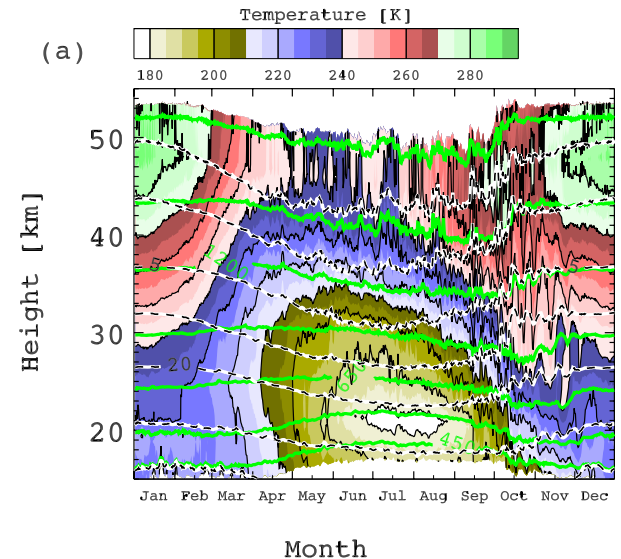

(b)

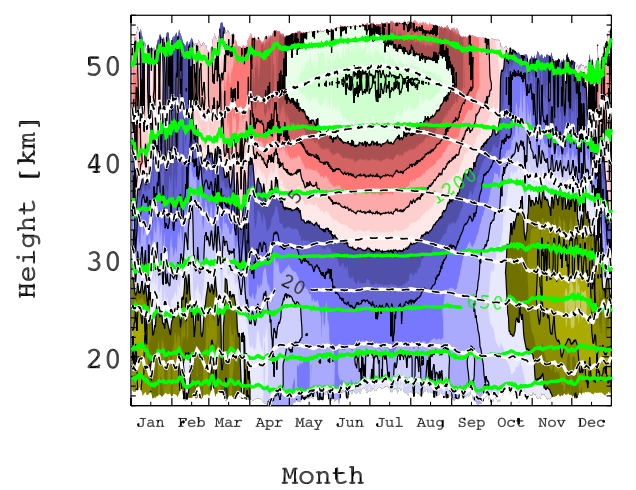

Fig. 8. As Fig. 7, but showing temperature. Pressure contours are shown (black dashes on white) for $1,2,5,10,20,50,100 \mathrm{hPa}$. (a) South of equivalent latitude $80 \mathrm{~S}$, (b) North of equivalent latitude 80 N. Data taken from ECMWF operational analyses.

is not possible because of dynamical constraints. Juckes $(2001,1997)$ show an alternative flow configuration is possible: mean outflow on the stratospheric portion of isentropes balanced by mean inflow on the tropospheric portions of the same isentropes.

From August the water vapour and methane fields at $40 \mathrm{~km}$ start to return to midlatitude stratospheric values as the vortex is broken up. This process starts later at lower altitudes. The overlay of the potential temperature contours shows that the spring descent is a different dynamical process to that occurring in the autumn. In the autumn the air mass is clearly crossing the isentropes, whereas in the spring the isentropes are also descending at a significant rate. Unlike the radiative cooling in autumn, which caused isentropes to rise and material contours to sink, the spring is a time of dynamically forced descent, carrying both isentropes and material contours downwards. ${ }^{4}$

\footnotetext{
${ }^{4}$ Such dynamically forced descent occurring below the level of forcing is often cited as evidence of "downward control" (Haynes et al., 1991), but the papers presenting this idea fail to distinguish
}

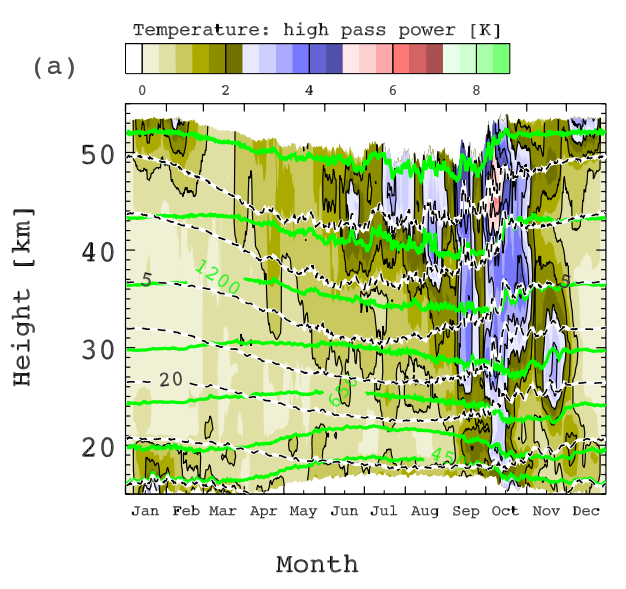

(b)

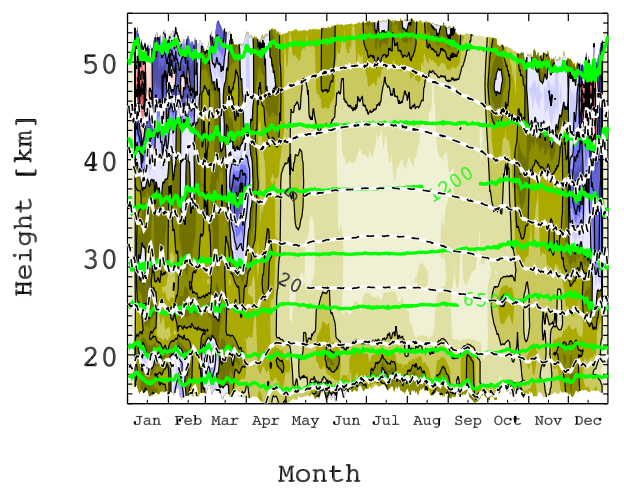

Fig. 9. As Fig. 8, but showing intensity of high pass temperature variability $\left(\sqrt{L P\left[(H P[T])^{2}\right]}\right)$, where the operator $L P$ is a low pass filter (a 10 day running mean) and $H P$ is a high pass filter, taken as the residual from $L P$.

Engel et al. (2006) observe a layer of mesospheric air in the arctic descending from $30 \mathrm{~km}$ in late January to $25 \mathrm{~km}$ in early March, 2003, and report a modelling study which shows this air descended during the previous autumn. This is highly consistent with the picture shown in Figs. 7e,f (lower left red arrow), where a tongue of low methane, high water vapour air persists and descends at a time when the layers higher in the stratosphere are returning to more typical stratospheric values. A similar pattern is seen in the southern hemisphere methane (Fig. 7c). The dynamics of this topdown vortex breakup is discussed by Lahoz et al. (1996).

The methane fields in both hemispheres suggest that there has been descent of around $20 \mathrm{~km}$ through the year, bringing air down from $40 \mathrm{~km}$ to $20 \mathrm{~km}$ while preserving its chemical composition. This compares with an estimate of $13 \mathrm{~km}$ made by Rex et al. (1999) based on a comparison between air inside and outside the vortex.

The water vapour shows a similar pattern, with the noticeable exception of anomalous loss in the southern winter as between diagnostic determination and causal determination. 

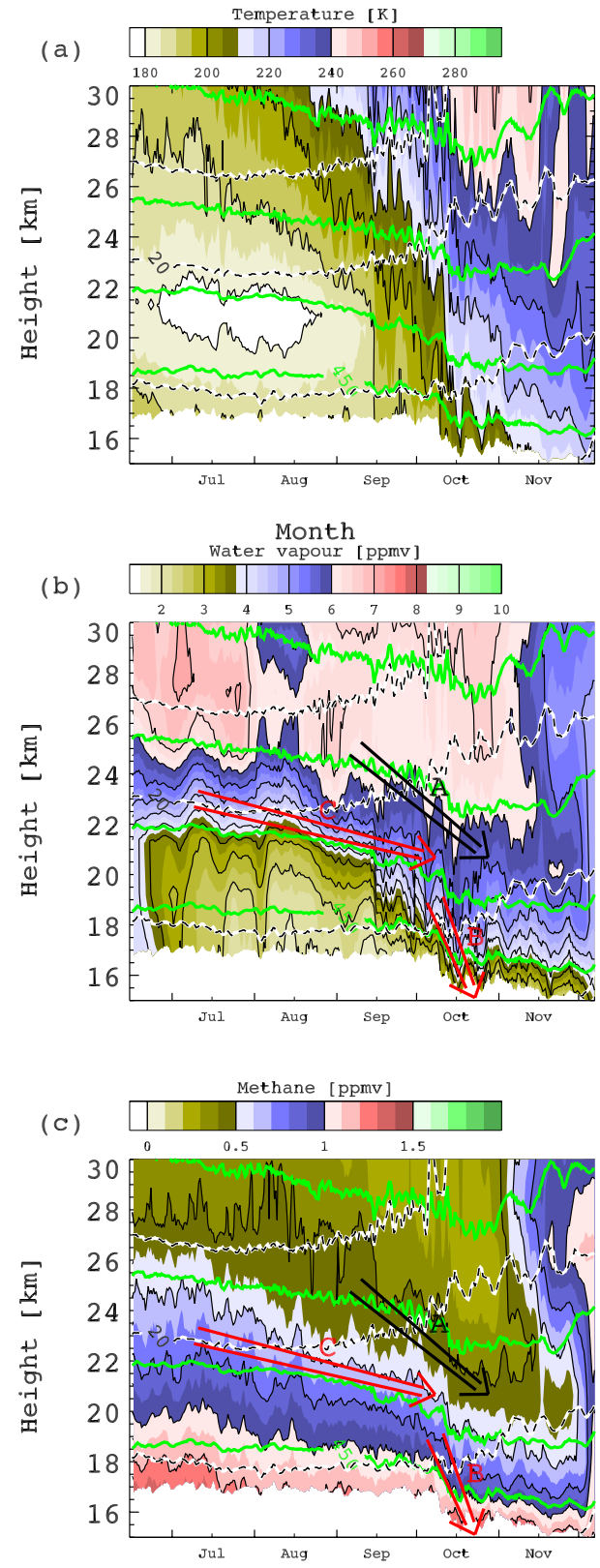

Fig. 10. Close up of (a) Fig. 8a, (b) Fig. 7b and (c) Fig. 7c, showing evolution through the end of the southern winter up to $30 \mathrm{~km}$. Arrows in (b) and (c) show descent rates of (A) $10^{-3} \mathrm{~ms}^{-1}$, (B) $3 \times 10^{-3} \mathrm{~ms}^{-1}$, and (C) $3 \times 10^{-4} \mathrm{~ms}^{-1}$.

the vapour freezes out (e.g. Benson et al., 2006). At $18 \mathrm{~km}$ the water vapour does not reappear when temperatures rise in September: in the last 2 weeks of September the temperatures are above $200 \mathrm{~K}$. The methane fields in this period imply that the air mass is conserved. The lack of recovery in water vapour concentrations suggesting that the condensate has settled out to some extent. The water vapour only recov- ers when, in October, the methane fields show that the air mass is no longer being preserved. At $20 \mathrm{~km}$, however, there appears to be a recovery in the water vapour concentrations in mid-September (Fig. 10b) at a time when the methane showing no signs of mixing (Fig. 10c). This may be caused by evaporation.

\section{Meteorology}

The equivalent latitude means give a useful overview of the annual cycle. This section looks at variability on shorter timescales. Figure 11 shows the analysed tracer fields during a break up of the northern polar vortex at $850 \mathrm{~K}$ (around $10 \mathrm{hPa}, 30 \mathrm{~km}$ at the pole). The corresponding flow field is illustrated using the potential vorticity in Fig. 12. The vortex is displaced from the pole and splits into two halves while an anticyclonic circulation is established over the pole. The ozone field at first mirrors the potential vorticity field, with the low ozone in the vortex core being advected around in the disturbed vortex. On 19 April, however, a new low centre appears in a region of low potential vorticity. The dynamical anomaly is a response to rapid meridional transport. This particular anomaly is discussed in more detail by Lahoz et al. (2007) as an example of a "frozen-in-anticyclone" (Manney et al., 2006). At this level ozone is subject to significant chemical evolution, and the ozone advected over the polar cap is being destroyed. The assimilation code used here does not have any explicit representation of chemistry but the consequences of the chemistry are nevertheless present in the analysis through the observations.

The methane and water vapour fields (Fig. 11) also show the break up of the vortex, but unlike the ozone field we see no evidence of chemistry. In the previous section it was noted that the chemistry of these species in the upper stratosphere starts to compete with vertical advection, but the faster horizontal advection can still be viewed as nearly conservative.

The analysis clearly shows the preservation of air mass properties as the vortex breaks up. It was shown in J2006 that the typical information retention time of the analysis was around 2 days. Beyond this time information from earlier observation is replaced by new observations. Thus, continuity of air mass properties for longer time scales must reflect continuity in the observations.

\section{Equivalent zonal means}

\subsection{Water vapour and methane}

We now look at latitude-height sections of fields averaged at constant equivalent latitude, referred to here as equivalent zonal means. Similar structures are visible in the simple zonal mean fields, but some of the detail is lost or blurred.

Mean fields are shown for January, April, July and October. The structure in the water vapour and methane fields is 

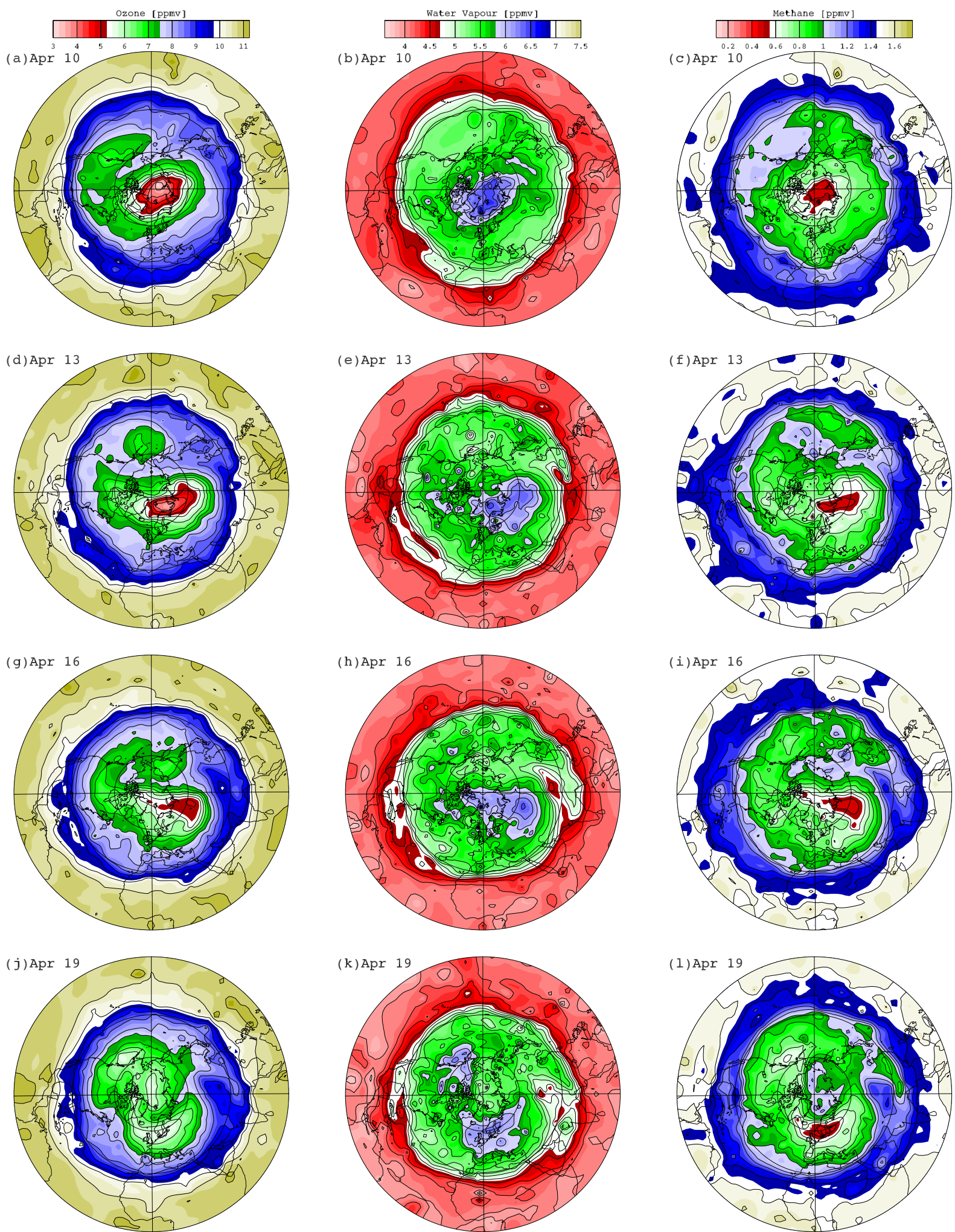

Fig. 11. Ozone (a, d, g, j: contour interval $0.5 \mathrm{ppmv})$, water vapour (b, e, h, k: contour interval $0.2 \mathrm{ppmv})$, and methane (c, f, i, l: contour interval $0.1 \mathrm{ppmv}$ ), on the 10th to 19 April 2003 (in steps of 3 days, starting at the top), on the $850 \mathrm{~K}$ isentropic surface, Northern polar stereographic projections. Ozone, water vapour and methane are assimilated from MIPAS level 2 data as described in the text. Each analysis is valid at 00:00 GMT. 

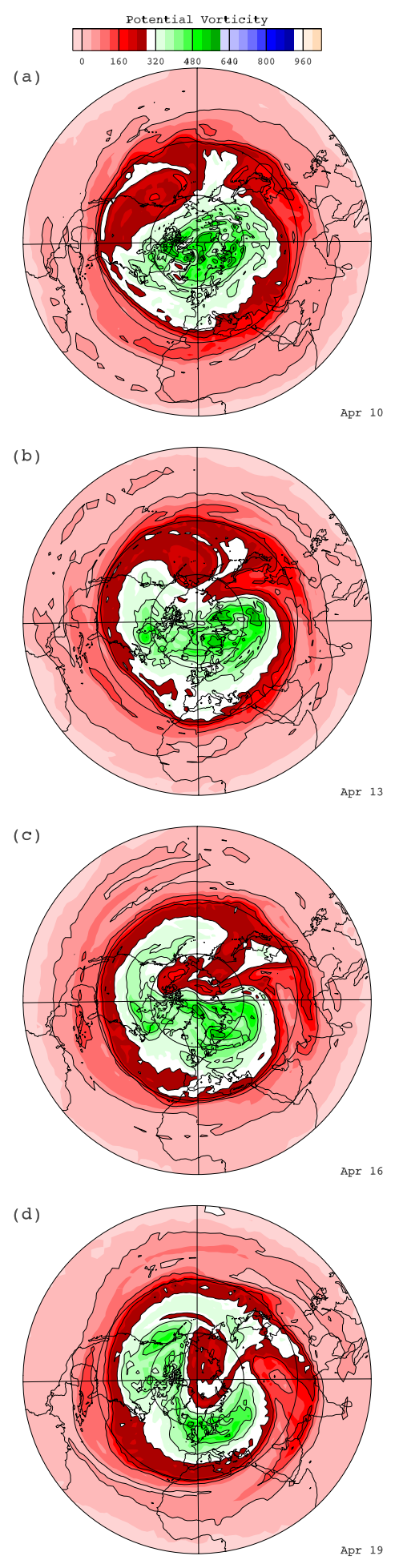

Fig. 12. As Fig. 11, except showing Ertel potential vorticity from the ECMWF operational analyses, contour interval $8 \times$ $10^{-5} \mathrm{~K} \mathrm{~kg}^{-1} \mathrm{~s}^{-1}$. The colour scale (top) is labeled in units of $10^{-6} \mathrm{~K} \mathrm{~kg}^{-1} \mathrm{~s}^{-1}$. consistent with that shown by Randel et al. (1998), based on HALOE and MLS data, even though that paper shows results from fitting an annual cycle to 7 years of data (1991 to 1997) rather than individual months as shown here.

Relative to that paper, the peaks in the water vapour fields shown in Figs. 13, 14 data are at about the same altitude but at higher concentrations (typically around 7.4 ppmv compared to 6.4 ppmv in Randel et al., 1998). Le Texier et al. (1998) model low water vapour concentrations being drawn down from the mesosphere into the winter polar vortex, with values as low as $4.5 \mathrm{ppmv}$ at $40 \mathrm{~km}$ at the winter pole. At this time and location Randel et al. (1998) show around 5.6 ppmv compared to around $6.5 \mathrm{ppmv}$ in the present analysis. Part of this difference may be explained by the high bias of MIPAS relative to HALOE. The extreme values are likely to include a contribution from the high noise in the MIPAS water vapour, especially at the summer poles (Fig. $2 b$ and Lahoz et al., 2006).

There is also detailed agreement between the methane fields of Fig. 13, 14 and Randel et al. In April methane concentrations below $0.6 \mathrm{ppmv}$ are drawn down to around $20 \mathrm{~km}$ in a small area at the centre of the northern vortex. This is also visible in Randel et al., although the $0.6 \mathrm{ppmv}$ contour ends slightly higher there. There is also agreement in the lower part of the southern surf-zone: between 20 and $30 \mathrm{~km}$ and between 20 and $60 \mathrm{~S}$ in Fig. 14b, e, latitudinal gradients have been weakened by strong horizontal mixing; there are also weak vertical gradients. Higher up there is a slight difference in structure, especially in July (Fig. 14b): here a broad region of level isopleths from $45 \mathrm{~S}$ almost to the equator. In Randel et al. (1998) the region of horizontal isopleths does not extend so far northwards. Another difference concerns the buckling of contours in the methane field at $30 \mathrm{~S}$, $30 \mathrm{~km}$ in July, and the matching pattern in the water vapour. There is a slight southward displacement of the isopleths at $25 \mathrm{~km}, 30 \mathrm{~S}$ between April (Fig. 13d, e) and July (Fig. 14a, b), but the southward displacement is substantially faster at $30 \mathrm{~km}$. Between April and July there is also a slight southward displacement of the isopleths at $25 \mathrm{~km}, 30 \mathrm{~N}$, such that the methane isopleths here are also buckled. A similar buckled structure is visible in the January methane field at $40 \mathrm{~km}$, $20 \mathrm{~N}$ (Fig. 13b). The absence of such details from Randel et al. (1998) is consistent with some loss of detail due to the smoothing which might be expected from the lower data volume then available and the consequent need to merge 7 years of data. This buckling is consistent with differential horizontal transport.

\subsection{Total observed hydrogen}

The main reactions affecting water vapour and methane in the stratosphere convert methane to water vapour, such that the the quantity "total observed hydrogen":

$H_{\mathrm{TO}} \stackrel{\text { def }}{=} 2\left[\mathrm{H}_{2} \mathrm{O}\right]+4\left[\mathrm{CH}_{4}\right]$, 

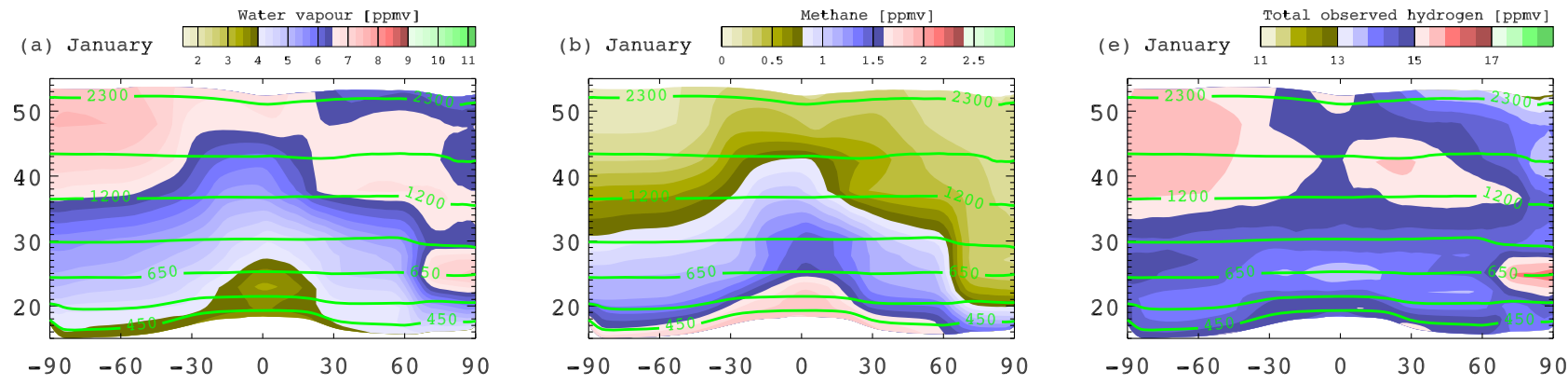

(d) April

(e) April

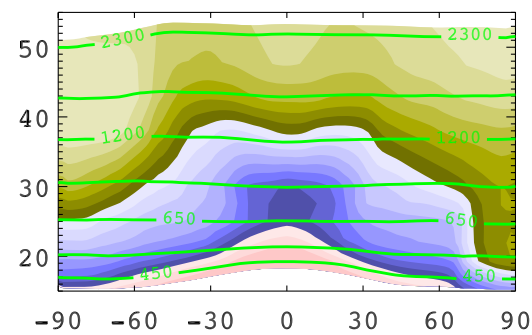

(f) April

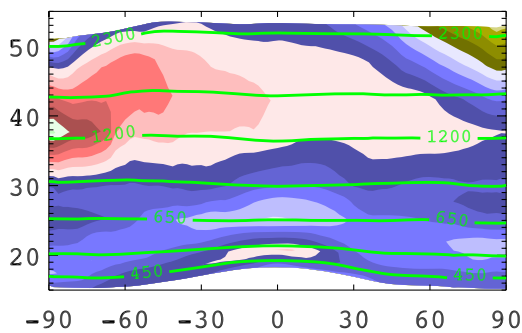

Fig. 13. Monthly, equivalent latitude means of water vapour, methane and total observed hydrogen $\left(H_{\mathrm{TO}}\right)$ for January, April. Fields shown are water vapour $(\mathbf{a}, \mathbf{d})$, methane $(\mathbf{b}, \mathbf{e})$ and $H_{\mathrm{TO}}(\mathbf{c}, \mathbf{f})$. Green contours show the heights of isentropic surfaces (these figures are generated from data on isentropic levels).
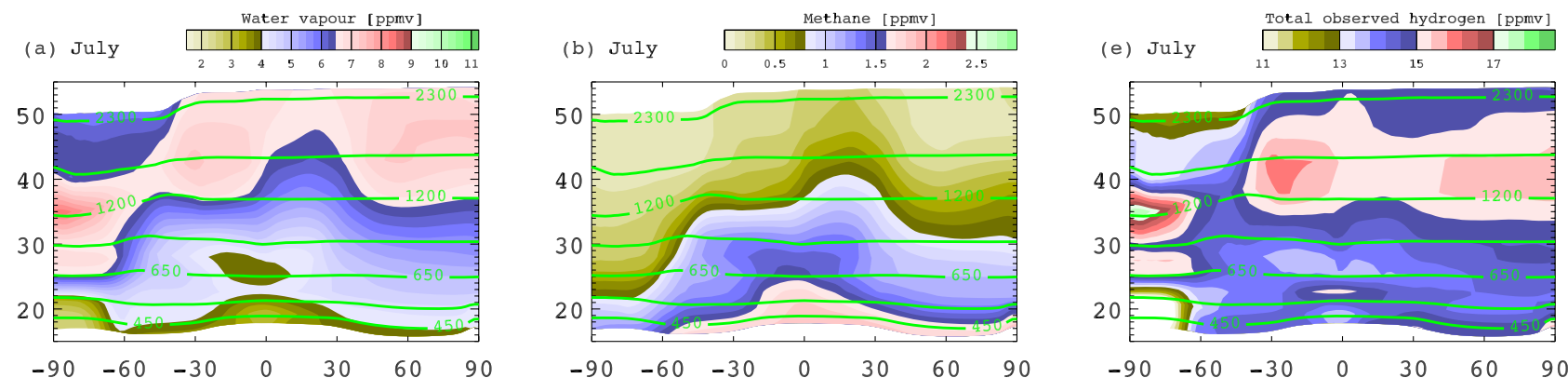

(d) October

(e) October

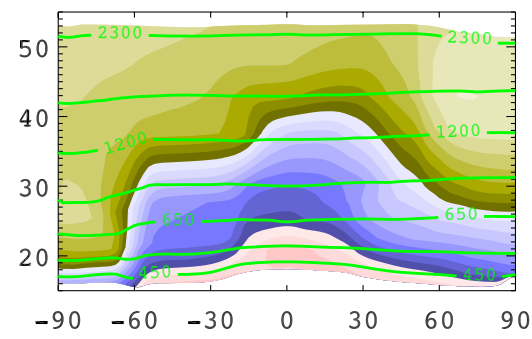

(f) October

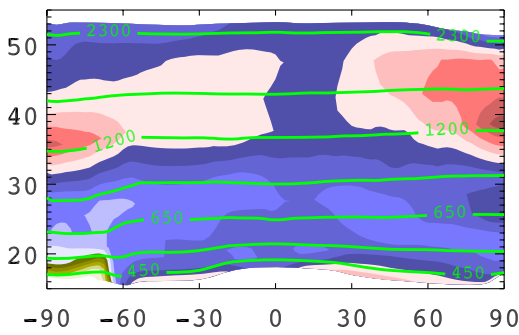

Fig. 14. As for Fig. 13, except for July, October.

is approximately conserved (e.g. Garcia and Solomon, 1994). Molecular hydrogen is also a significant component of the total hydrogen budget in the mesosphere, but is not included in the observations used here. The last column in figures 13 and 14 displays the equivalent zonal mean $H_{\mathrm{TO}}$. Figure $13 \mathrm{f}$ can be compared to Fig. 8 of Randel et al. (1998), showing $H_{\mathrm{TO}} / 2$ from HALOE, CLAES and MLS for 1991-1997: that study found $H_{\mathrm{TO}}$ to be nearly constant with height. The higher upper stratospheric water vapour values found in the present analysis are also reflected in higher $H_{\mathrm{TO}}$. 

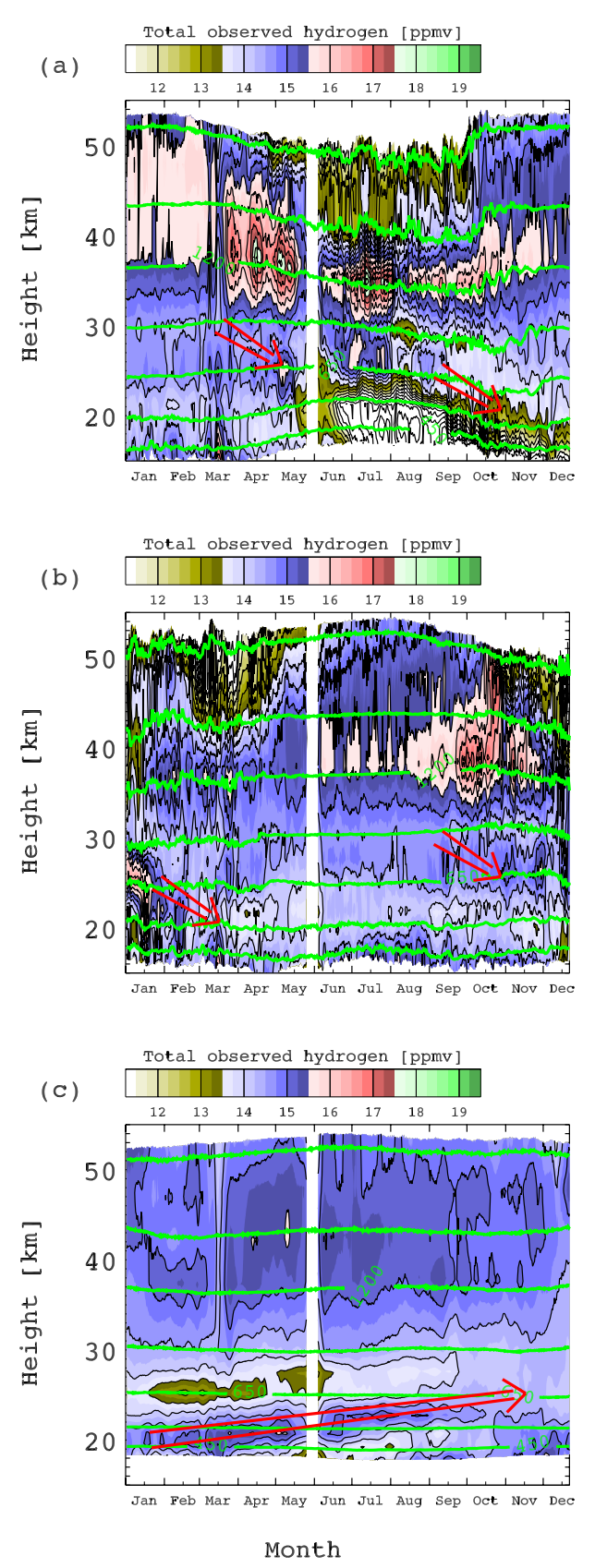

Fig. 15. As Fig. 7, but showing total observed hydrogen.

In both the winter poles there is a strong low anomaly in the mesosphere where there is known to be downward advection. This is due to photo-dissociation of water vapour in the upper mesosphere into hydrogen and oxygen (Harries et al., 1996). As the air is advected down the hydrogen is oxidized back to water vapour, explaining the recovery of $H_{\mathrm{TO}}$.

In the tropics the alternating maxima and minima of the "tropical tape-recorder" are visible. The anomalies have a broader structure, especially in April, than the corresponding features in the water vapour field (compare Figs. 13d and 13f). The sharp horizontal boundaries in the water vapour field reflect, in part, the effect of differential vertical advection on the strong vertical gradients. In the $H_{\mathrm{TO}}$ field the absence of strong vertical gradients rules out this mechanism. Figure 15 shows $H_{\text {TO }}$ fields corresponding to the water vapour and methane fields of Fig. 7. The $H_{\mathrm{TO}}$ "tape-recorder" signal is also clearly visible in Fig. 15c. However, the signal to noise ratio in the field is generally low.

The large band of positive anomalies across the upper stratosphere is an unexplained structure in Fig. 13c,f and Fig. $14 \mathrm{c}$,f, with $H_{\mathrm{TO}}$ values exceding $15 \mathrm{ppmv}$ over large regions. Nassar et al. (2005) present data from the ACE-FTS instrument for February to April 2004. They show a fall in $H_{\mathrm{TO}}$ (presented as "equivalent water" which is exactly half $H_{\mathrm{TO}}$ ) above $60 \mathrm{~km}$, averaged over $30 \mathrm{~N}$ to $66 \mathrm{~N}$. Figure 1 of Nassar et al. (2005) also shows a weak peak in $H_{\mathrm{TO}}$ between 50 and $60 \mathrm{~km}$, however, the amplitude is less than the error bars and the altitude is higher than the peak found here (around $40 \mathrm{~km}$ at that time and latitude, albeit for a different year). HALOE observations (Randel et al., 1998) do not show any such upper stratospheric maximum. The maximum in the MIPAS analysis might be due do observational error. An alternative, suggested by Hannegan et al. (1998), is that there is a significant source (of the order or $2 \mathrm{Tg} /$ year) of water vapour in the upper atmosphere from cometary material. This would be advected into the stratosphere in the form of $\mathrm{H}_{2}$ and then mixed out. Some support for the latter theory is seen in the high values observed in the mid-stratosphere polar vortex during the winter. Figure 16 illustrates how high $H_{\mathrm{TO}}$ values coincide with the centre of the vortex and very low ozone values ( $2.75 \mathrm{ppmv})$, where it would be advected by the mean descent, suggesting that there is some truth in the high values. Figures 17 shows an equivalent snapshot in the southern hemisphere. The $H_{\mathrm{TO}}$ field is noisier here. There is again a contrast between the tropics and high latitudes, but here the change takes place mainly across the sub-tropical barrier, not across the vortex boundary. The time height sections (Fig. 15a, b) do not, however, show smooth descent comparable with that seen in the methane fields. The low signal to noise ratio of the $H_{\mathrm{TO}}$ field prevent a clear picture from emerging.

There is an alternative explanation for the apparent material advection of excess $H_{\mathrm{TO}}$. Geer et al. (2006) show that MIPAS ozone fields have a positive bias in the centre of the ozone hole: the retrieval is unable to reproduce the near zero values measured there by sondes and by HALOE. The values of methane in the centre of the vortex are also extremely small (Figs. 16, 17), following oxidation to water vapour in the mesosphere. It is possible that the retrieval is, as with ozone, introducing a small positive bias in these circumstances. Such a bias would be co-located with the low methane values and so would appear to be advected conservatively.

The high $H_{\mathrm{TO}}$ could also result from an error in water vapour, but it is not clear why such an error should occur 


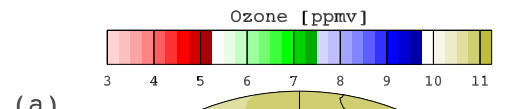

(a)
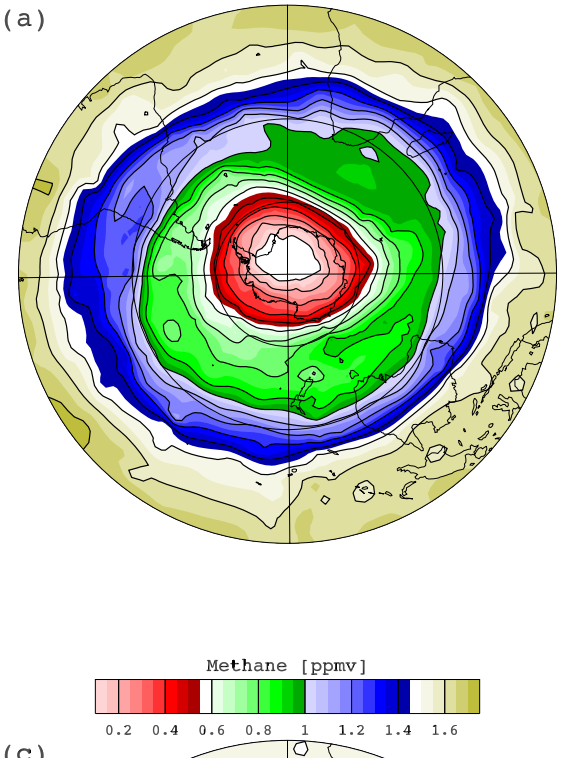

(c)

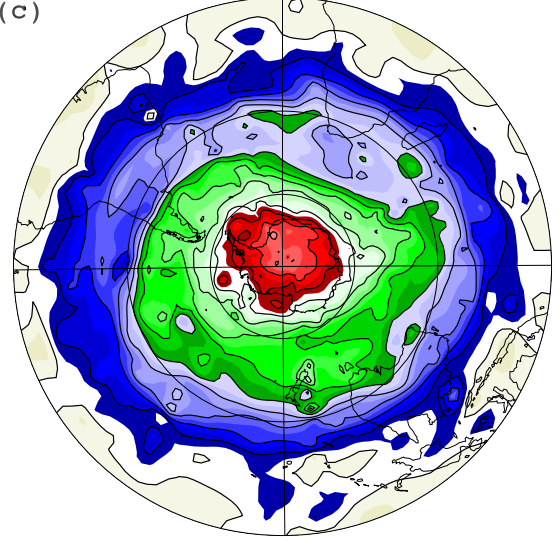

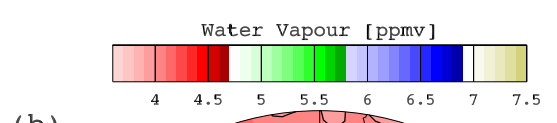

(b)

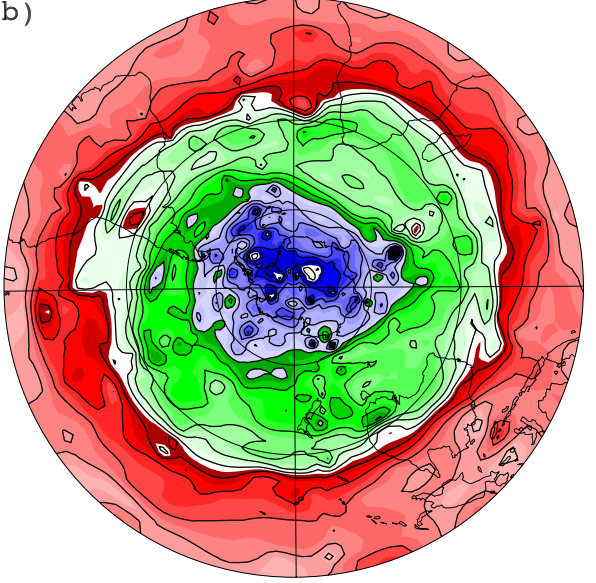

(d)

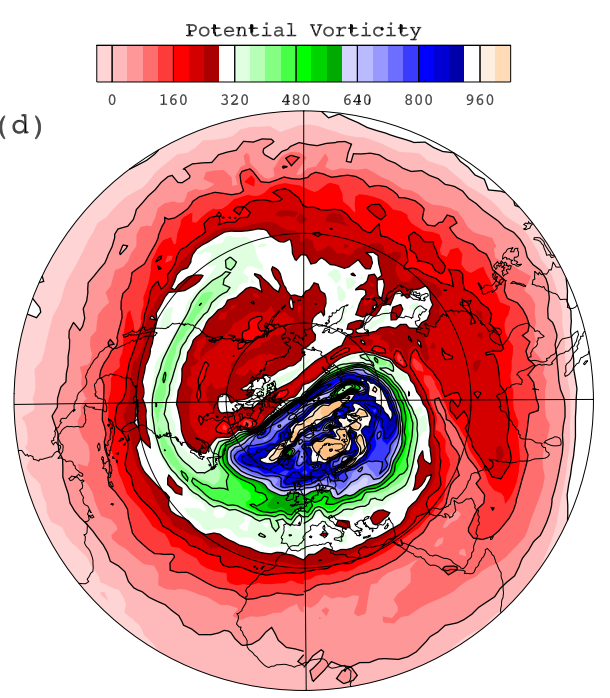

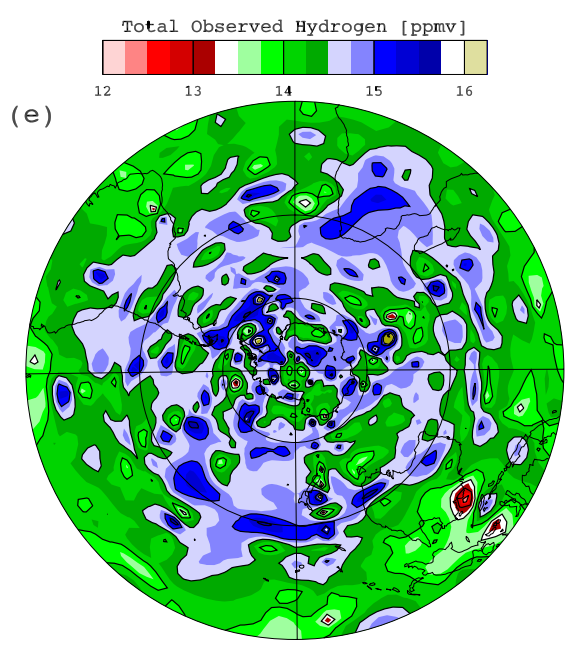

Fig. 16. (a) Ozone, (b) water vapour, (c) methane, (d) Ertel potential vorticity and (e) $H_{\mathrm{TO}}$ on 20 December 2003. All are northern polar stereographic plots on the $850 \mathrm{~K}$ isentropic surface. 

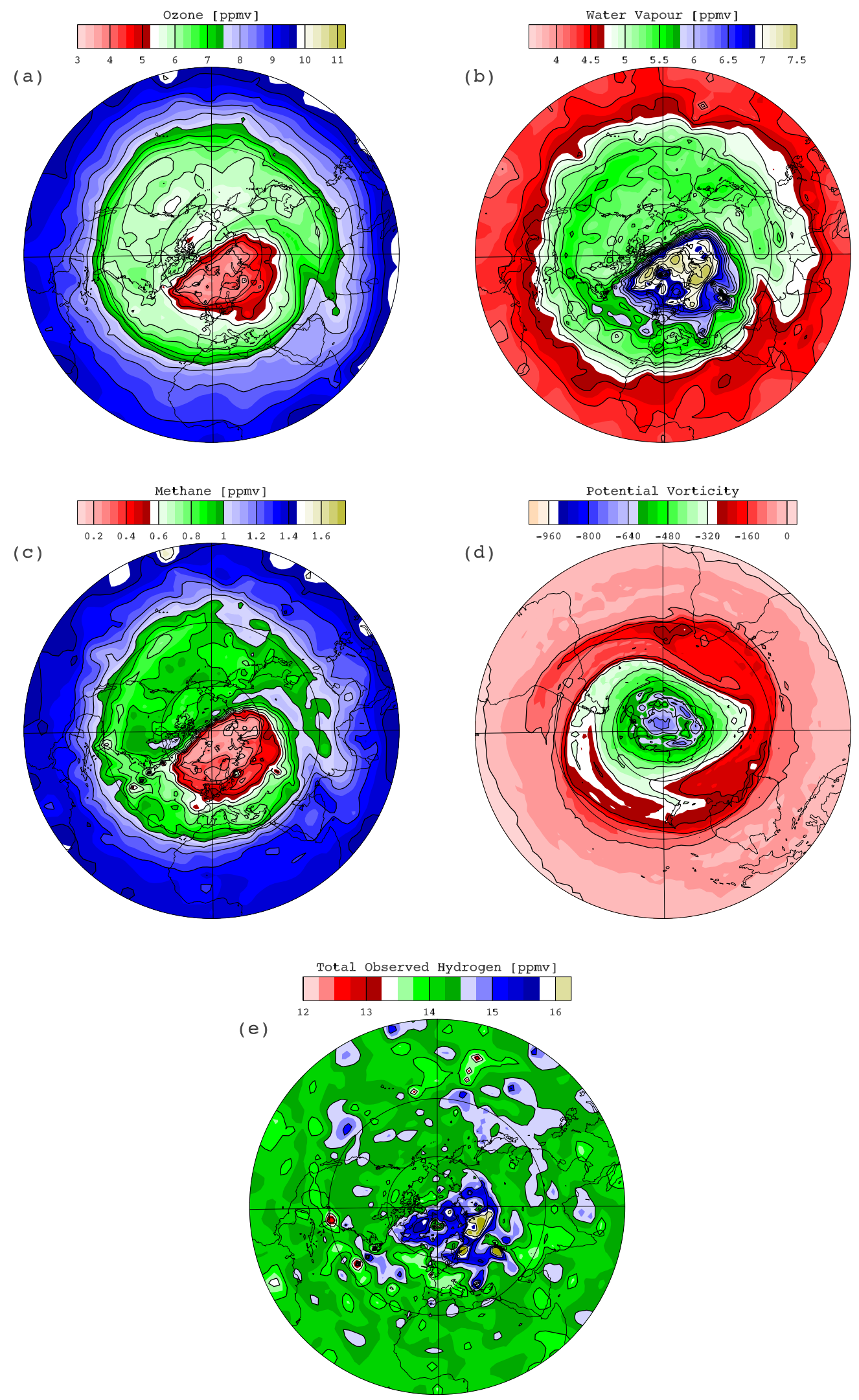

Fig. 17. As Fig. 16, except southern polar stereographic plots for 20 April 2003. 
both in the upper stratosphere and the winter polar vortex.

\section{Conclusions}

The MIPAS ozone, water vapour and methane fields have been used to construct gridded fields for the whole of 2003. Comparison with independent observations shows good agreement: the standard deviations are mostly lower than those obtained in nearest-neighbour comparisons with validating instruments, showing that added value is obtained from the assimilation process.

For ozone the mean bias relative to other instruments is generally less than $5 \%$ in amplitude up to $1250 \mathrm{~K}$. Above that height the ozone analyses appear to have a negative bias, though the agreement with HALOE remains good up to $2000 \mathrm{~K}$. The standard deviation is generally between 5 and $10 \%$, agreement with HALOE being best above $1000 \mathrm{~K}$ and agreement with SAGE II \& III being best below this level. In water vapour the analyses generally have a high bias of 5 to $10 \%$ relative to HALOE up to $2400 \mathrm{~K}$. Standard deviations relative to HALOE are as low as $5 \%$ in the lower stratosphere, but larger relative to other instruments and relative to HALOE in the upper stratosphere. The water vapour biases relative to POAM III and SAGE II vary with height, between $1250 \mathrm{~K}$ and $1500 \mathrm{~K}$ there is little bias relative to POAM III, but the standard deviations are close to $20 \%$. For methane, the analyses are high relative to HALOE, though this bias is less than 5\% through much of the stratosphere. The standard deviation grows from around $7 \%$ at $500 \mathrm{~K}$ to $20 \%$ at $3000 \mathrm{~K}$.

In combination, the analyses of the 3 gases provide a rich record of transport processes through the year in the stratosphere. In the tropics, both water vapour and "observed total hydrogen" $\left(H_{\mathrm{TO}}\right.$, defined here as the hydrogen content of the observed methane and water vapour) fields show a clear "tape recorder" signal, indicating an ascent rate in the tropical lower stratosphere of around $2 \times 10^{-4} \mathrm{~ms}^{-1}$, consistent with earlier studies.

At high latitudes, both water vapour and methane show a deep region of descent within the polar vortex, with a rate of around $10^{-3} \mathrm{~ms}^{-1}$ in the mid stratosphere [24 to $26 \mathrm{~km}$ ], $3 \times 10^{-4} \mathrm{~ms}^{-1}$ in the lower stratosphere [20 to $24 \mathrm{~km}$ ] and a short period of faster descent $\left(3 \times 10^{-3} \mathrm{~ms}^{-1}\right)$ at the end of the winter in the lowermost stratosphere. In the course of the winter the $0.5 \mathrm{ppmv}$ methane isopleth descends from around $40 \mathrm{~km}$ to $20 \mathrm{~km}$.

In the winter mesosphere the $H_{\mathrm{TO}}$ values are depleted, as found by Harries et al. (1996), who conclude that water vapour has been photolysed to molecular hydrogen.

Between 40 and $50 \mathrm{~km}$ there is a band of enhanced $H_{\mathrm{TO}}$ values in the analyses. This could result from enhanced hydrogen content in the mesosphere, produced by deposition of cometary material in the atmosphere, being advected down and then oxidised to become observable in the upper stratosphere. However, the evidence is patchy and the anomaly may be due to instrumental biases. To explain the measurements any such error must have the property of being conserved following the mesospheric air mass as it descends in the nascent stratospheric polar vortices. A (hypothetical) bias associated with extremely low methane would satisfy this condition.

Acknowledgements. This work was funded by NERC through BADC. I am grateful for all the data used in this study, which was of high quality and provided freely from the sources cited. I would like to thank A. Dhudhia and C. Piccolo for help with the MIPAS data. I would also like to thank A. Geer and an anonymous reviewer for helpful criticism of this work.

Edited by: W. Ward

\section{References}

Benson, C. M., Drdla, K., Nedoluha, G. E., Shettle, E. P., Hoppel, K. W., and Bevilacqua, R. M.: Microphysical modeling of southern polar dehydration during the 1998 winter and comparison with POAM III observations, J. Geophys. Res., 111, D07201, doi:10.1029/2005JD006506, 2006.

Brühl, C., Drayson, S. R., II, J. M. R., Crutzen, P. J., McInerney, J. M., Purcell, P. N., Claude, H., Gernandt, H., McGee, T. J., McDermid, I. S., and Gunson, M. R.: Halogen occultation experiment ozone channel validation, J. Geophys. Res., 101, $10217-$ $10240,1996$.

Crutzen, P. and Arnold, F.: Nitric-acid cloud formation in the cold antarctic stratosphere - a major cause for the springtime ozone hole, Nature, 324, 651-655, 1986.

Crutzen, P. and Lelieveld, J.: Human impacts on atmospheric chemisty, Ann. Rev. Earth Plan. Sci., 29, 17-45, 2001.

Dunkerton, T.: Quasi-biennial and subbiennial variations of stratospheric trace constituents derived from HALOE observations, J. Atmos. Sci., 58, 7-25, 2001.

Engel, A., Möbius, T., Haase, H.-P., Bönisch, H., Wetter, T., Schmidt, U., Levin, I., Reddmann, T., Oelhaf, H., Wetzel, G., Grunow, K., Huret, N., and Pirre, M.: On the observation of mesospheric air inside the arctic stratospheric polar vortex in early 2003, Atmos. Chem. Phys., 6, 267-282, 2006, http://www.atmos-chem-phys.net/6/267/2006/.

ESA: MIPAS product handbook, European Space Agency, ESRIN, Frascati, Italy, available from envisat.esa.int/dataproducts, 2004.

Farman, J. C., Gardiner, B. G., and Shanklin, J. D.: Large losses of total ozone in Antarctica reveal seasonal $\mathrm{ClOx} / \mathrm{NOx}$ interaction, Nature, 315, 207-210, 1985.

Fischer, H. and Oelhaf, H.: Remote sensing of vertical profiles of atmospheric trace constituents with MIPAS limb-emission spectrometers, Appl. Opt., 35, 2787-2796, 1996.

Fonteyn, D., Lahoz, W., Geer, A., Dethof, A., Wargan, K., Stajner, I., Pawson, S., Rood, R., Bonjean, S., Chabrillat, S., Daerden, F., and Errera, Q.: MIPAS ozone assimilation, in: Proceedings of the Second Workshop on the Atmospheric Chemistry Validation of ENVISAT (ACVE-2), European Space Agency, 2004.

Funke, B., López-Puertas, M., Gil-López, S., von Clarmann, T., Stiller, G. P., Fischer, H., and Kellmann, S.: Downward transport of upper atmospheric $\mathrm{NO}_{\mathrm{X}}$ into the polar strato- 
sphere and lower mesosphere during the Antarctic 2003 and Arctic 2002/2003 winters, J. Geophys. Res., 110, D24308, doi:10.1029/2005JD006463, 2005.

Garcia, R. and Solomon, S.: A new numerical-model of the middle atmosphere. 2. Ozone and related species, J. Geophys. Res (D), 99, 12 937-12 952, 1994.

Geer, A. J., Lahoz, W. A., Bekki, S., Bormann, N., Errera, Q., Eskes, H. J., Fonteyn, D., Jackson, D. R., Juckes, M. N., Massart, S., Peuch, V.-H., Rharmili, S., and Segers, A.: The ASSET intercomparison of ozone analyses: method and first results, Atmos. Chem. Phys., 6, 5445-5474, 2006,

http://www.atmos-chem-phys.net/6/5445/2006/.

Glatthor, N., Von Clarmann, T., Fischer, H., Funke, B., Grabowski, U., Hopfner, M., Kellmann, S., Kiefer, M., Linden, A., Milz, M., Steck, T., Stiller, G., Tsidu, G., and Wang, D.: Mixing processes during the antarctic vortex split in september-october 2002 as inferred from source gas and ozone distributions from ENVISATMIPAS, J. Atmos. Sci., 62, 787-800, 2005.

Hannegan, B., Olsen, S., Prather, M., Zhu, X., Rind, and Lerner, J.: The dry stratosphere: a limit on cometary influx, Geophys. Res. Lett., 25, 1649-1652, 1998.

Harries, J., Ruth, S., and Russell, J.: On the distribution of mesospheric molecular hydrogen inferred from HALOE measurements of $\mathrm{H}_{2} \mathrm{O}$ and $\mathrm{CH}_{4}$, Geophys. Res. Lett., 23, 297-300, 1996.

Haynes, P. H., McIntyre, M. E., Shepherd, T. G., Marks, C. J., and Shine, K. P.: On the "Downward Control" of Extratropical Diabatic Circulations by Eddy-Induced Mean Zonal Forces, J. Atmos. Sci., 48, 651-678, 1991.

Juckes, M. and Lawrence, B.: Data assimilation for re-analyses: potential gains from full use of post-analysis-time observations, Tellus A, 58, 171-178, doi:10.1111/j.1600-0870.2006.00167.x, 2006.

Juckes, M. N.: The mass flux across the tropopause : Quasigeostrophic theory, Q. J. R. Meteorol. Soc., 123, 71-99, 1997.

Juckes, M. N.: A generalization of the transformed Eulerian-mean meridional circulation, Q. J. Royal Meteorol. Soc., 127, 147$160,2001$.

Juckes, M. N.: Evaluation of MIPAS ozone fields assimilated using a new algorithm constrained by isentropic tracer advection, Atmos. Chem. Dyn., 6, 1549-1565, 2006.

Lahoz, W., O’Neill, A., Heaps, A., Pope, V., Swinbank, R., Harwood, R., Froidevaux, L., Read, W., Waters, J., and Peckham, G.: Vortex dynamics and the evolution of water vapour in the stratosphere of the southern hemisphere, Quart. J. Roy. Meteorol. Soc., 122, 423-450, 1996.

Lahoz, W. A., Geer, A. J., and O'Neill, A.: Dynamical evolution of the 2003 southern hemisphere stratospheric winter using Envisat trace-gas observations, Quart. J. Roy. Meteorol. Soc., 19852008, 2006.

Lahoz, W. A., Geer, A. J., and Orsolini, Y. J.: Northern hemisphere stratospheric summer from MIPAS observations, Quart. J. Roy. Meteorol. Soc., 133, 197-211, 2007.

Le Texier, H., Solomon, S., and Garcia, R.: The role of molecular hydrogen and methane oxidation in the water vapour budget of the stratosphere, Quart. J. Roy. Meteorol. Soc., 114, 281-295, 1998.

Lumpe, J. D., Fromm, M., Hoppel, K., Bevilacqua, R. M., Randall, C. E., Browell, E. V., Grant, W. B., McGee, T., Burris, J., Twigg, L., Richard, E. C., Toon, G. C., Sen, B.,
Boesch, H., Fitzenberger, R., and Pfeilsticker, K.: Comparison of POAM III ozone measurements with correlative aircraft and balloon data during SOLVE, J. Geophys. Res., 108(D5), 8316, doi:10.1029/2001JD000472 [2002], 2003.

Manney, G., Livesey, N., Jimenez, C., Pumphrey, H., Santee, M., Mackenzie, I., and Waters, J.: EOS microwave limb sounder observations of "frozen-in" anticyclonic air in arctic summer, Geophys. Res. Letts., 33, L06810, doi:10.1029/2005GL025418, 2006.

McIntyre, M. E.: The Stratospheric Polar Vortex and Sub-Vortex: Fluid Dynamics and Midlatitude Ozone Loss, Phil. Trans. Phys. Sci. Eng., 352, 227-240, 1995.

Milz, M., Von Clarmann, T., Fischer, H., Glatthor, N., Grabowski, U., Hopfner, M., Kellmann, S., Kiefer, M., Linden, A., Tsidu, G., Steck, T., Stiller, G., Funke, B., Lopez-puertas, M., and Koukouli, M.: Water vapor distributions measured with the Michelson Interferometer for Passive Atmospheric Sounding on board ENVISAT (MIPAS/ENVISAT), J. Geophys. Res (D), 110, D24307, doi:10.1029/2005JD005973, 2005.

Mote, P., Rosenlof, K., Mcintyre, M., Carr, E., Gille, J., Holton, J., Kinnersley, J., Pumphrey, H., Russell, J., and Waters, J.: An atmospheric tape recorder: the imprint of tropical tropopause temperatures on stratospheric water vapor, J. Geophys. Res (D), 101, 3989-4006, 1996.

Mote, P., Dunkerton, T., Mcintyre, M., Ray, E., Haynes, P., and Russell, J.: Vertical velocity, vertical diffusion, and dilution by midlatitude air in the tropical lower stratosphere, J. Geophys. Res (D), 103, 8651-8666, 1998.

Nassar, R., Bernath, P., Boone, C., Manney, G., Mcleod, S., Rinsland, C., Skelton, R., and Walker, K.: Stratospheric abundances of water and methane based on ACE-FTS measurements, Geophys. Res. Lett., 32, L15S04, doi:10.1029/2005GL022383, 2005.

Pan, L., Randel, W., Massie, S., Kanzawa, H., Sasano, Y., Nakajima, H., Yokota, T., and Sugita, T.: Variability of polar stratospheric water vapor observed by ILAS, J. Geophys. Res. (Atmos.), 107, 8214, doi:10.1029/3001JD001164, 2002.

Payne, V.: Retrieval of Water Vapour and Methane from the MIPAS, Ph.D. thesis, Oxford University, 2005.

Pierce, R. B., Al-Saadi, J., Fairlie, T. D., Natarajan, M., Harvey, V. L., Grose, W. L., Russell, J. M., Bevilacqua, R., Eckermann, S. D., Fahey, D., Popp, P., Richard, E., Stimpfle, R., Toon, G. C., Webster, C. R., and Elkins, J.: Large-scale chemical evolution of the arctic vortex during the 1999/2000 winter: HALOE/POAM III lagrangian photochemical modeling for the SAGE III-ozone loss and validation experiment (SOLVE) campaign, J. Geophys. Res., 108(D5), 8317, doi:10.1029/2001JD001063, 2003.

Planet, W. G., Miller, A. J., Horvath, K., Nagatani, R., Flynn, L., Hilsenrath, E., Kondragunta, S., Cebula, R. P., and DeLand, M. T.: Total ozone determinations from NOAA operational SBUV/2 observations: an update, J. Geophys. Res., 106(D15), 17 471-17 478, 2001.

Randel, W., Wu, F., Russell, J., Roche, A., and Waters, J.: Seasonal cycles and QBO variations in stratospheric $\mathrm{CH}_{4}$ and $\mathrm{H}_{2} \mathrm{O}$ observed in UARS HALOE data, J. Atmos. Sci., 55, 163-185, 1998.

Randel, W. J., W., F., Vömel, H., Nedoluha, G. E., and Forster, P.: Decreases in stratospheric water vapor after 2001: Links to changes in the tropical tropopause and the 
Brewer-Dobson circulation, J. Geophys. Res., 111, D12312, doi:10.1029/2005JD006744, 2006.

Rex, M., Salawitch, R., Toon, G., Sen, B., Margitan, J., Osterman, G., Blavier, J., Gao, R., Donnelly, S., Keim, E., Neuman, J., Fahey, D., Webster, C., Scott, D., Herman, R., May, R., Moyer, E., Gunson, M., Irion, F., Chang, A., Rinsland, C., and Bui, T.: Subsidence, mixing, and denitrification of arctic polar vortex air measured during POLARIS, J. Geophys. Res (D), 104, 26611$26623,1999$.

Rind, D. and Lonergan, P.: Modeled impacts of stratospheric ozone and water-vapor perturbations with implications for high-speed civil transport aircraft, J. Geophys. Res (D), 100, 7381-7396, 1995.

Rosenfield, J. E., Newman, P. A., and Schoeberl, M. R.: Computations of diabatic descent in the stratospheric polar vortex, J. Geophys. Res., 99(D8), 16677-16690, doi:10.1029/94JD01156, 1994.

Rosenlof, K., Oltmans, S., Kley, D., Russell, J., Chiou, E., Chu, W., Johnson, D., Kelly, K., Michelsen, H., Nedoluha, G., Remsberg, E., Toon, G., and McCormick, M.: Stratospheric water vapor increases over the past half-century, Geophys. Res. Lett., 28 (7), 1195-1198, 2001.

Russell, J., Gordley, L., Park, J., Drayson, S., Hesketh, W., Cicerone, R., Tuck, A., Frederick, J., Harries, J., and Crutzen, P.: The halogen occultation experiment, J. Geophys. Res (D), 98, 10777-10797, 1993.

Schoeberl, M., Luo, M., and Rosenfield, J.: An Analysis of the Antarctic HALOE Trace Gas Observations, J. Geophys. Res., 100, 5159-5172, 1995.
Shindell, D.: Climate and ozone response to increased stratospheric water vapor, Geophys. Res. Lett., 28, 1551-1554, 2001.

Shine, K.: The greenhouse effect and stratosheric change, in: NATO ASI 18, edited by Chanin, M.-L., 285-300, Springer-Verlag, Berlin, 1993.

Solomon, S., Portmann, R. W., Sasaki, T., Hofmann, D. J., and Thompson, D. W. J.: Four decades of ozonesonde measurements over antarctica, J. Geophys. Res (D), 110, D21311, doi:10.1029/2005JD005917, 2005.

Thomason, L. W. and Taha, G.: SAGE III aerosol extinction measurements: initial results, Geophys. Res.Lett., 30, 33-1-33-4, doi:10.1029/2003GL017317, 2003.

Tsidu, G. M., Kiefer, M., von Clarmann, T., Fischer, H., Funke, B., Grabowski, U., Hase, F., Höpfner, M., López-Puertas, M., and Stiller, G. P.: Validation of MIPAS/ENVISAT level-1b data products, H.-L. Huang, D. Lu, Y. Sasano (Eds.), Optical Remote Sensing of the Atmosphere and Clouds III, Proc. of SPIE, 4891, 483-496, 2003.

von Savigny, C., Haley, C. S., Sioris, C. E., McDade, I. C., Llewellyn, E. J., Degenstein, D., Evans, W. F. J., Gattinger, R. L., Griffoen, E., Lloyd, N., McConnell, J. C., McLinden, C. A., Murtagh, D. P., Solheim, B., and Strong, K.: Stratospheric ozone profiles retrieved from limb scattered sunlight radiance spectra measured by the OSIRIS instrument on the ODIN satellite, Geophys. Res. Lett., 30, 1755-1758, doi:10.1029/2002GL016401, 2003. 